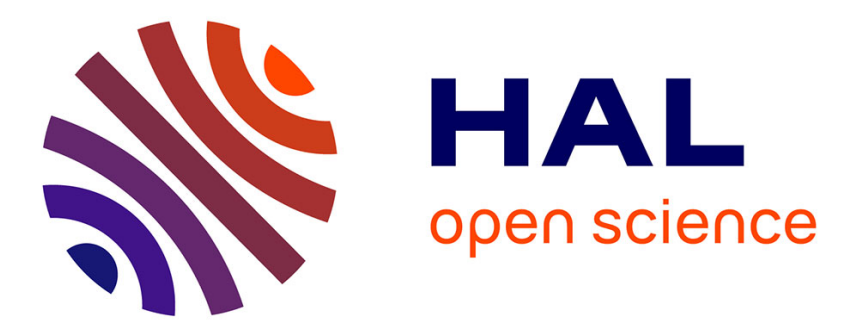

\title{
Does sophistication of the weighting scheme enhance the performance of long-short commodity portfolios?
}

\author{
Hossein Rad, Rand Low, Joelle Miffre, Robert Faff
}

\section{To cite this version:}

Hossein Rad, Rand Low, Joelle Miffre, Robert Faff. Does sophistication of the weighting scheme enhance the performance of long-short commodity portfolios?. Journal of Empirical Finance, 2020, 10.1016/j.jempfin.2020.05.006 . hal-02868473

\section{HAL Id: hal-02868473}

\section{https://hal-audencia.archives-ouvertes.fr/hal-02868473}

Submitted on 15 Jun 2020

HAL is a multi-disciplinary open access archive for the deposit and dissemination of scientific research documents, whether they are published or not. The documents may come from teaching and research institutions in France or abroad, or from public or private research centers.
L'archive ouverte pluridisciplinaire HAL, est destinée au dépôt et à la diffusion de documents scientifiques de niveau recherche, publiés ou non, émanant des établissements d'enseignement et de recherche français ou étrangers, des laboratoires publics ou privés. 


\title{
Does sophistication of the weighting scheme enhance the performance of long-short commodity portfolios?
}

\author{
Hossein Rad ${ }^{\mathrm{a}, *}$, Rand Kwong Yew Low ${ }^{\mathrm{a}}$, Joëlle Miffre ${ }^{\mathrm{b}}$, Robert Faffa \\ ${ }^{a}$ UQ Business School, University of Queensland, Brisbane, 4072, Australia \\ ${ }^{b}$ Audencia Business School, 8 Route de la Jonelière, 44312, Nantes, France;
}

\begin{abstract}
The article develops a long-short portfolio construction technique that captures the fundamentals of backwardation and contango present in commodity futures markets and simultaneously deviates from the equal-weighting scheme traditionally employed in the literature. The sophisticated weighting schemes based on risk minimization and risk timing are found to dominate the traditional naive allocation and the schemes based on utility maximization. The conclusion applies to both momentum and term structure portfolios and persists after accounting for transaction costs, lack of liquidity, various model specifications, and different sub-periods.

Keywords: long-short portfolios, equal weights, optimized weights, risk-timing weights JEL classifications: G13, G14
\end{abstract}

\footnotetext{
The paper has benefited from discussions with J. Fan, M. Prokopczuk, K. Walsh and participants at the Griffith Alternative Investments 2016 conference, Gold Coast, Australia, at the Energy and Commodity Finance 2017 conference, Oxford, UK, and at the 2017 International Accounting and Finance Doctoral Symposium, Warsaw, Poland.

${ }^{*}$ Corresponding author.

Email addresses: h.rad@business.uq.edu.au (Hossein Rad), r.low@business.uq.edu.au (Rand Kwong Yew Low), jmiffre@audencia.com (Joëlle Miffre), r.faff@business.uq.edu.au (Robert Faff)
} 


\section{Introduction}

There are theoretical and empirical reasons to believe that commodity futures investments command positive risk premia. The theoretical considerations relate either to the theory of storage of Kaldor (1939) where the risk premium depends on inventory levels, and thus on the slope of the futures curve, or to the hedging pressure hypothesis of Cootner (1960) where the risk premium is a function of hedgers' net positions. These theories have been empirically validated in numerous empirical studies ${ }^{1}$ that advocate long positions in backwardated futures and short positions in contangoed futures. ${ }^{2}$ While less theoretically grounded, other signals have also been shown to successfully predict commodity futures price changes, where these signals relate to past performance, ${ }^{3}$ value, volatility, open interest, or skewness (Erb and Harvey, 2006; Miffre and Rallis, 2007; Hong and Yogo, 2012; Asness et al., 2013; Szymanowska et al., 2014; Fernandez-Perez et al., 2018; Miffre, 2016, for a review.)

In the pre-cited empirical studies, the scheme employed to weight commodities within a portfolio is equal weight. The rationale for this naive choice comes from the fact that unlike in equity markets, there is no natural value-weighting scheme that can be easily applied to commodity portfolios; the closest equivalent (i.e., production and consumption weighting) is difficult to implement given the challenges of collecting reliable inventory data (Gorton et al., 2013; Symeonidis et al., 2012). ${ }^{4}$

Our contribution is to relax the assumption of naive equal weights and to apply sophisticated weighting schemes to the design of long-short commodity portfolios. These schemes emanate from the equity literature and are based on an optimization procedure (Markowitz, 1952; DeMiguel

\footnotetext{
${ }^{1}$ Support for the theory of storage is provided in Fama and French (1987), Erb and Harvey (2006), Gorton and Rouwenhorst (2006), Symeonidis et al. (2012), Gorton et al. (2013), and Szymanowska et al. (2014). Evidence in favor of the hedging pressure hypothesis can be found in Bessembinder (1992), De Roon et al. (2000), and Basu and Miffre (2013).

${ }^{2}$ Backwardation predicts a rise in commodity futures prices driven by scarce inventories, a downward-sloping term structure of futures prices, or net short hedging. Conversely, contango predicts a drop in commodity futures prices driven by abundant inventories, an upward-sloping term structure, or net long hedging.

${ }^{3}$ Past performance or momentum has been shown to capture the phases of backwardation and contango as winners (losers) present backwardated (contangoed) characteristics such as positive (negative) roll-yields, net short (long) hedging and low (high) standardized inventories (Miffre and Rallis, 2007; Gorton et al., 2013).

${ }^{4}$ The required data on inventories is to be collected in reference to the delivery place of the underlying asset of the futures contracts and is not always publicly available. Furthermore, inventories are often revised after being published, making it difficult to analyze the profitability of the signals.
} 
et al., 2009; Kolm et al., 2014) or risk timing (Fletcher, 2011; Kirby and Ostdiek, 2012). More specifically, we consider i) five optimization schemes based on variance minimization or various utility maximization and ii) five risk-timing schemes (three of them follow Kirby and Ostdiek $(2012)^{5}$ and define portfolio weights based on volatility timing (VT), beta timing (BT), and reward-to-risk timing (RRT); the other two are novel to the literature on portfolio construction and are based on Value-at-Risk (VaR) and conditional Value-at-Risk (CVaR)).

The idea is to apply the aforementioned weighting schemes to the construction of commoditybased long-short momentum and term structure portfolios. By doing this, the proposed optimized and risk-timing strategies not only capture the fundamentals of backwardation and contango that are key to the pricing of commodity futures, they also assign sophisticated weights to the constituents of these portfolios. We can then compare the performance of the proposed sophisticated momentum and term structure strategies to that of their naive equal-weight counterparts and thereby test whether sophistication in the weighting schemes as based on an optimization procedure or risk timing enhances performance.

Our findings suggest that the naive-weighting scheme traditionally employed in the construction of long-short commodity portfolios is easily challenged by the use of sophisticated weighting schemes. Momentum and term structure strategies based on weights that minimize or time risk yield more than their naive counterparts based on equal weights. At the other end of the spectrum, strategies based on utility maximization lead to extreme long-short weights and poor risk-adjusted performance. These conclusions persist after accounting for the risks of the strategies as captured by the model of Bakshi et al. (2017). They are also robust to the consideration of transaction costs, lack of liquidity, and different sub-periods and to the use of different parameters in the weighting algorithms.

The article contributes to the literature on portfolio construction by proposing a novel approach that designs long-short portfolios based on optimized and risk-timing weights. Designing such a long-short framework is crucial as volatility timing weights are by construction positive and

\footnotetext{
${ }^{5}$ The timing strategies of Kirby and Ostdiek (2012) are close in nature to risk parity strategies, where portfolio weights depend on the contribution of each asset to the risk of the entire portfolio.
} 
optimized weights of either sign tend to be extreme in the presence of estimation errors, leading to high turnover, poor out-of-sample performance, and trivial investment practicality (Jagannathan and Ma, 2003; Michaud, 2008; Kirby and Ostdiek, 2012; Low et al., 2016). The article also speaks to the literature on portfolio performance and, more specifically, to that on the relative merits of various weighting schemes (DeMiguel et al., 2009; Tu and Zhou, 2011; Kirby and Ostdiek, 2012; Kolm et al., 2014). By showing that risk-timing portfolios can outperform equal-weight portfolios in the context of long-short asset allocation strategies, our article extends to a long-short setting the conclusions that Kirby and Ostdiek (2012) drew in a long-only setting.

The remainder of the paper is structured as follows. Sections 2 and 3 present the research method and the dataset, respectively. Section 4 discusses the empirical results. Section 5 provides robustness checks and finally, section 6 concludes.

\section{Research method}

This section centers on portfolio construction with a focus on how to calculate naive and sophisticated weights of either sign.

\subsection{Allowing for weights of either sign}

Since commodity futures markets switch from backwardation to contango depending on supply and demand shocks, commodity futures strategies should freely allow for long, as well as short, weights. The simplest way to accommodate this specificity is by removing short-selling constraints from the optimization function, thereby allowing for weights of either sign. Unfortunately, this leads to extreme weights in the presence of estimation errors, poor out-of-sample performance, and trivial investment practicality (Jagannathan and Ma, 2003; Michaud, 2008; Kirby and Ostdiek, 2012). Allowing for negative weights within the risk-timing strategies of Kirby and Ostdiek (2012) is not trivial either: the approach defines portfolio weights based on various risk measures, which by definition are strictly positive.

To accommodate the need for negative weights, we adapt the portfolio construction method-

ology used for long-only portfolios as follows. First, we decipher whether a given commodity is backwardated or contangoed and consequently, whether it shall be bought or sold. Second, over 
the ranking period used to define the optimized weights, the returns of the contangoed commodities are multiplied by -1 and the returns on the backwardated commodities are left unchanged. Third, the matrix of returns thereby obtained is used to define $X=\left(x_{1}, \cdots, x_{N}\right)^{\prime}$, a $N \times 1$ vector of positive weights ensuring that the conditions of full collateralization and full investment are imposed; namely, $\Sigma_{i=1}^{N} x_{i}=1$. Section 2.2.2 (Section 2.2.3) details how these weights are estimated for the optimized (risk-timing) portfolios. Fourth, to reflect upon the fact that contangoed futures shall be sold, the positive weights obtained for contangoed commodities are multiplied by -1 and the long-short portfolio thereby constructed is held over the next month. The approach is rolled forward a month and at that time a new portfolio is constructed.

Two signals are used to tell apart whether a given commodity futures is backwardated or contangoed in the first step above. The first signal for the momentum portfolio is based on past performance, measured as excess return over the 12 months preceding portfolio formation, where a positive (negative) excess return triggers a long (short) recommendation. The second signal for the term structure portfolio is based on roll-yield measured at the time of portfolio formation as the differential in the $\log$ of the settlement prices of the nearby and second nearby contracts; a positive (negative) roll-yield prompts a long (short) position. The motivation comes from the fact that commodities with good past performance or positive roll yields are in backwardation and thus expected to appreciate, while commodities with poor past performance or negative roll yields are in contango and thus expected to depreciate.

Our naive and sophisticated momentum portfolios do not merely invest in extreme performers; rather, they consider the $N$ assets present at the time of portfolio formation. As such, they resemble the time-series trend-following portfolios of Szakmary et al. (2010) and Moskowitz et al. (2012) that are based on equal weights. Equivalently, our naive and sophisticated term structure portfolios could be regarded as time-series term structure portfolios. Such a time-series approach ensures better diversification and allows for the consideration of a wider range of portfolios. Indeed, depending on market conditions, the portfolios formed may be long-only (shall all futures be backwardated), short-only (shall all futures be contangoed) or long-short (shall some futures be backwardated, while others are contangoed). By contrast, the cross-sectional approach typically considered in the 
literature (e.g., Erb and Harvey, 2006; Miffre and Rallis, 2007) consistently forces the portfolios to be long-short.

\subsection{Weighting schemes}

This section details how the positive weights implied by the long-only naive, optimized and risktiming strategies are obtained. As noted in Section 2.1, these positive weights are subsequently transformed into negative weights for contangoed assets to reflect upon the fact that contangoed assets shall be sold. To enable fair comparison, the optimized and risk-timing weights are calculated using rolling-windows of one year of daily data.

\subsubsection{EQUALly-WEIGHTED (EW) APPROACH}

Portfolio weights are naively assumed to be the same across assets; i.e., $X_{t}=\left(\frac{1}{N}, \ldots, \frac{1}{N}\right)^{\prime}$. The weights do not depend on any parameter (aside from the number of assets) and thus the approach is appealing as it does not suffer from estimation errors. The equally-weighted (EW) momentum and term structure portfolios are standard in the commodity pricing literature and will serve as benchmarks to appraise the potential benefits emanating from the use of sophisticated weights.

\subsubsection{Optimized Weights}

Three of the five optimized solutions considered maximize, at time $t$, investor's expected utility of

wealth at time $t+1$ with respect to portfolio weights: $\max _{x_{i, t}} E_{t}\left[U\left(W_{t+1}\right)\right]$. Without loss of generality, we normalize investor's initial wealth to 1 , and therefore have

$$
W_{t+1}=W_{t}\left(1+r_{p, t+1}\right)=W_{t}\left(1+\Sigma_{i=1}^{N} x_{i} r_{i, t+1}\right)=1+\Sigma_{i=1}^{N} x_{i} r_{i, t+1},
$$

under the constraints of positive weights $x_{i} \geq 0, \quad i=1, \ldots, N$, full investment and full collateralization $\Sigma_{i=1}^{N} x_{i}=1$. Portfolio weights are defined under the following utility functions:

- Power utility (PU):

$$
U(W)=\frac{W^{1-\gamma}-1}{1-\gamma}, \gamma \neq 1
$$


- Negative exponential utility (NE):

$$
U(W)=\frac{-e^{-\eta W}}{\eta}, \eta \geq 0
$$

- Power utility with disappointment aversion (DA) and 0 as the reference point relative to which gains and losses are measured (Gul, 1991):

$$
U(W)= \begin{cases}\frac{W^{1-\gamma}-1}{1-\gamma} & \text { if } \quad W>0 \\ \frac{W^{1-\gamma}-1}{1-\gamma}+\left(\frac{1}{A}-1\right)\left[\frac{W^{1-\gamma}-1}{1-\gamma}\right] & \text { if } \quad W \leqslant 0\end{cases}
$$

$\gamma$ is the coefficient of relative risk aversion $(\gamma=3), \eta$ is the coefficient of absolute risk aversion $(\eta=3), A \leq 1$ is the coefficient of disappointment aversion $(A=0.6)$, where $A$ captures the fact that investors are more sensitive to losses than to gains of equal size.

Portfolio weights are also calculated for a mean-variance (MV) portfolio:

$$
\max _{X_{t}}\left(X_{t}^{\prime} \mu-\frac{\gamma}{2} X_{t}^{\prime} \Sigma X_{t}\right)
$$

where $X_{t}$ is the vector of weights and $\mu$ and $\Sigma$ are the estimated excess returns vector and covariance matrix, respectively. Lastly, we consider the minimum variance (MIN) portfolio, assuming therefore that expected returns can be ignored.

\subsubsection{RISK-TIMING WEIGHTS}

The risk-timing schemes employed do not use any formal optimization and as such, they are often considered as feasible alternatives to the optimized solutions (the latter are known to lead to extreme weights and poorly diversified allocation). In total, we consider five risk-timing schemes; three define asset allocation based on volatility timing, beta timing, and reward-to-risk timing (Kirby and Ostdiek, 2012); the other two are based on tail risk as modelled via Value-at-Risk and conditional Value-at-Risk; to the best of our knowledge, they are novel to the literature on portfolio construction. 
VOLATILITY TIMING (VT) WEIGHTS

The first class of risk-timing weights uses exclusively the assets' time-varying volatilities. This is done by setting all off-diagonal elements of the covariance matrix to zero. ${ }^{6}$ Formally, portfolio weights are given by

$$
x_{i, t}=\frac{1 / \sigma_{i, t}^{2}}{\sum_{i=1}^{N} 1 / \sigma_{i, t}^{2}}, \quad i=1,2, \cdots, N
$$

By introducing a tuning parameter, $\eta$, in the above equation, the VT strategy is generalized to allow for more flexibility in terms of how aggressive the portfolio weights respond to changes in volatility

$$
x_{i, t}=\frac{\left(1 / \sigma_{i, t}^{2}\right)^{\eta}}{\sum_{i=1}^{N}\left(1 / \sigma_{i, t}^{2}\right)^{\eta}}, \quad i=1,2, \cdots, N, \quad \eta \geq 0
$$

As $\eta \longrightarrow 0$, the effect of volatilities on determining portfolio weights diminishes and the strategy moves towards the EW strategy. As $\eta \longrightarrow \infty$, the strategy assigns larger weights to assets with lower volatility.

REWARD-TO-RISK TIMING (RRT) APPROACH

Although expected returns are usually estimated with far less precision than volatilities (Merton, 1980), treating them as part of the portfolio construction process enhances the available information set which can lead to better performance. The second class of risk-timing weights therefore incorporates conditional expected returns in Equation 6 as follows

$$
x_{i, t}=\frac{\left(\mu_{i, t}^{+} / \sigma_{i, t}^{2}\right)^{\eta}}{\sum_{i=1}^{N}\left(\mu_{i, t}^{+} / \sigma_{i, t}^{2}\right)^{\eta}}, \quad i=1,2, \cdots, N, \quad \eta \geq 0
$$

\footnotetext{
${ }^{6}$ The assumption of zero return correlations reduces estimation error and turnover, resulting in potentially enhanced net performance.
} 
$\mu_{i, t}^{+}=\max \left\{0, \mu_{i, t}\right\}$, where $\mu_{i, t}$ denotes average excess returns as estimated for asset $i$ at time $t$. The restriction $\mu_{i, t}^{+} \geq 0$ is needed for the RRT term structure portfolio to ensure that $x_{i, t} \geq 0, \quad \forall i, t ;^{7}$ it is redundant for the RRT momentum portfolio for which $\mu_{i, t}^{+} \geq 0$ and thus $x_{i, t} \geq 0$ by default. The base case RRT strategy assumes $\eta=1$.

\section{Beta timing (BT) APPROACH}

The third class of risk-timing weights addresses concerns pertaining to the high degree of estimation errors in sample expected returns (Merton, 1980). This is done by estimating conditional expected returns using the conditional CAPM as follows

$$
E_{t}\left(r_{i, t+1}\right)=\beta_{i, t} E_{t}\left(r_{M, t+1}\right), \quad i=1,2, \cdots, N,
$$

where $r_{i, t+1}$ and $r_{M, t+1}$ denote the time $t+1$ excess return of asset $i$ and that of the market, respectively. To ensure $x_{i, t} \geq 0, \quad i=1,2, \cdots, N$, we assign strictly positive weights to the assets whose betas have the same sign as the conditional expected return of the market. Replacing expectations with sample moments in Equation 8 and $\mu_{i, t}^{+}$by $\beta_{i, t}^{+}$in Equation 7 , the BT weights are defined as

$$
x_{i, t}=\frac{\left(\beta_{i, t}^{+} / \sigma_{i, t}^{2}\right)^{\eta}}{\sum_{i=1}^{N}\left(\beta_{i, t}^{+} / \sigma_{i, t}^{2}\right)^{\eta}}, \quad i=1,2, \cdots, N, \quad \eta \geq 0,
$$

where $\beta_{i, t}^{+}=\left|\beta_{i, t}\right|$ if $\beta_{i, t}$ has the same sign as $\mu_{M, t}$ and 0 otherwise (to ensure $x_{i, t} \geq 0 \quad$ for $\quad i=$ $1,, N) . \beta_{i, t}$ and $\mu_{M, t}$ in turn are estimated in relation to the daily excess returns of the S\&P-GSCI. As before for VT and RRT, the base case BT strategy assumes $\eta=1$.

\section{VALUE-AT-Risk Timing (VART) APPROACH}

Volatility is the sole risk influencing the VT weights. However, it suffers from the shortcomings of focusing on upside (as well as downside) volatility and of ignoring tail risk. To address these

\footnotetext{
${ }^{7}$ To ensure $x_{i, t} \geq 0$ for $i=1,2, \cdots, N$ in Equation 7 , the RRT term structure strategy assigns zero weights to the contangoed commodities with negative roll-yields and negative past performance (in that case, $\mu_{i, t}^{+}=0$ and $\left.x_{i, t}=0\right)$ and strictly positive weights to the contangoed commodities with negative roll-yields and positive past performance (in that case, $\mu_{i, t}^{+}=\mu_{i, t}$ and $x_{i, t}>0$ ). As contangoed assets with negative roll-yields shall be sold, these positive weights are subsequently multiplied by -1 (as detailed in Section 2.1).
} 
problems, we estimate Value-at-Risk timing weights which employ VaR in lieu of volatility in Equation 6

$$
x_{i, t}=\frac{\left(1 / \nu_{i, t}^{2}\right)^{\eta}}{\sum_{i=1}^{N}\left(1 / \nu_{i, t}^{2}\right)^{\eta}}, \quad i=1,2, \cdots, N, \quad \eta \geq 0,
$$

where $\nu$ denotes the $\alpha$ level empirical VaR. We set $\alpha=0.95$ which is among the most-frequently used values for VaR in practice (Low et al., 2013). Again, the base case Value-at-Risk timing (VaRT) strategy assumes $\eta=1$.

Conditional Value-at-Risk timing (CVaRT) approach

VaR suffers from two known shortcomings; that of ignoring the magnitude of losses greater than VaR and that of not being a coherent risk measure (Artzner et al., 1999), resulting in the underestimation of extreme losses. Conditional Value-at-Risk (CVaR), also known as expected shortfall, circumvents these issues by reporting the expected value of losses below the corresponding VaR threshold. CVaR is subadditive and convex, thus it is a coherent risk measure. It is also easier to estimate (Rockafellar and Uryasev, 2002). The conditional Value-at-Risk timing (CVaRT) weights are calculated by substituting VaR with CVaR in Equation 10

$$
x_{i, t}=\frac{\left(1 / c_{i, t}^{2}\right)^{\eta}}{\sum_{i=1}^{N}\left(1 / c_{i, t}^{2}\right)^{\eta}}, \quad i=1,2, \cdots, N, \quad \eta \geq 0,
$$

where $c$ denotes the $\alpha$ level empirical CVaR and $\alpha=0.95$. The base case CVaRT strategy assumes $\eta=1$.

\section{Data and sampling}

The dataset, from Datastream International, consists of daily prices for 40 commodity futures from January 1979 to April 2016. The constituents of the dataset comprise 10 metal commodity futures (aluminum, copper, gold, lead, nickel, palladium, platinum, silver, tin, zinc), 4 livestock (feeder cattle, frozen pork bellies, lean hogs, live cattle), 9 energy contracts (Brent crude oil, coal, electricity, gas oil, gasoline, heating oil, light sweet crude oil, natural gas, unleaded gasoline), 14 agricultural commodities (cocoa, coffee, corn, cotton, frozen concentrated orange juice, oats, rough 
rice, soybeans, soybean meal, soybean oil, sugar number 11, sugar number 14, wheat, white wheat), alongside with the futures on lumber, milk and western plywood. Our study assumes that investors hold fully-collateralized positions in these contracts. Excess returns are measured as the percent changes in the daily settlement prices using either nearest or second nearest contracts; the second nearest contracts are used in months when the nearest contracts mature. This approach addresses potential liquidity issues.

We will compare the performance of the naive and sophisticated momentum and term structure portfolios to benchmarks that are now standard in the commodity pricing literature (Erb and Harvey, 2006; Miffre and Rallis, 2007; Szymanowska et al., 2014; Bakshi et al., 2017). These include: i) AVG, a long-only equally-weighted and monthly-rebalanced portfolio of all commodity futures, ii) the S\&P-GSCI, iii) CARRY, an equally-weighted monthly-rebalanced portfolio that is long the 5 commodity futures with highest roll-yields and short the 5 commodities with lowest roll-yields, iv) MOM, an equally-weighted monthly-rebalanced portfolio that is long the 5 commodity futures with highest mean excess returns over the past 6 months and short the 5 commodity futures with lowest mean excess returns over the past 6 months and v) LIQ, a long-short portfolio that is long the 5 commodity futures with lowest "Amivest" measure of liquidity and short the 5 commodity futures with highest "Amivest" measure of liquidity (Amihud et al., 1997; Marshall et al., 2012). ${ }^{8}$ Appendix A presents summary statistics for these portfolios. Aligned with the literature (Miffre, 2016), the long-short portfolios generate better performance than the long-only benchmarks.

\section{Main empirical results}

\subsection{Momentum strategies}

Can the optimized and risk-timing strategies proposed in Section 2 be used to enhance the performance of the standard (EW) momentum strategy? Table 1, Panel A answers the question by looking at various performance measures. With Sharpe and Sortino ratios at 0.74 and 1.08 respectively, the naive EW momentum strategy ranks 5th out of the 11 momentum strategies considered.

\footnotetext{
${ }^{8}$ Amivest measure is calculated as the average over the 2 months preceding portfolio formation of the ratio of daily \$volume (or volume multiplied by settlement price) to daily absolute return.
} 
MIN and VT are shown to present the highest Sharpe ratios (0.97 and 0.95, respectively), the highest Sortino ratios (1.45 and 1.50, respectively) and the highest Omega ratios (2.12 and 2.06, respectively). VaRT and CVaRT rank closely thereafter with e.g., Sharpe ratios at 0.87 and Sortino ratios exceeding 1.3. At the other end of the spectrum, the momentum strategies that maximize expected utility rank worst with e.g., Sharpe ratios around 0.3.

The outperformance of MIN, VT, VaRT and, CVaRT relative to EW does not come from a better gross performance (the mean excess returns obtained are often statistically the same). Rather the higher Sharpe, Sortino and Omega ratios of MIN, VT, VaRT, and CVaRT are driven by their more appealing risk profiles; namely, their lower volatility, lower downside volatility, lower maximum drawdown, higher VaR or higher CVaR. The strategies based on expected utility maximization suffer from risk characteristics that are unattractive such as annualized total and downside volatilities exceeding 25\%, negative skewness levels or maximum drawdowns of more than $75 \%$. These high levels of risk are driven by the poorly diversified asset allocation that optimizers are known to generate (Jagannathan and Ma, 2003; Michaud, 2008; Kirby and Ostdiek, 2012). ${ }^{9}$

[Table 1 about here.]

Table 1, Panel B reports parameter estimates from regressions of the excess returns of the sophisticated momentum strategies onto the excess returns of the naive EW momentum strategy. Confirming the results of Panel A, MIN, VT, VaRT, and CVaRT stand out as better strategies than EW since they generate abnormal excess returns that are significant at the $1 \%$ level. The risk-adjusted outperformance of MIN, VT, VaRT, and CVaRT ranges from $1.2 \%$ to $2.4 \%$ a year. Interestingly, the sensitivity of the MIN, VT, VaRT, and CVaRT excess returns to the EW excess returns is less than 1, confirming that indeed these strategies are less risky than the EW benchmark. The strategies based on utility maximization again stand poorly relative to the competing portfolios, destroying investors wealth relative to the EW benchmark by an average alpha at $5.34 \%$ a year.

Table 1, Panel C reports similar parameter estimates as Table 1, Panel B but this time we treat as independent variables the excess returns of the three-factor model of Bakshi et al. (2017);

\footnotetext{
${ }^{9}$ Detailed asset allocations for all strategies are available upon request from the authors.
} 
namely, AVG, CARRY, and MOM. The idea is to test whether the proposed naive and sophisticated momentum strategies merely capture the risk premia known to be present in commodity futures markets or whether they are capable of generating positive and significant alphas.

MIN, VT, VaRT, and CVaRT stand out again; they present exposures to MOM that are lower than those of the other portfolios, as well as positive and statistically significant alphas ranging from $4.40 \%(\mathrm{MIN})$ to $5.30 \%(\mathrm{VT})$ a year. Likewise, EW and RRT generate positive alphas that are statistically significant at the $1 \%$ level. Unlike AVG and CARRY, the MOM factor strongly and uniformly explains the excess returns of all strategies. This is not surprising as the portfolios studied in Table 1 sort commodities into backwardated and contangoed portfolios based on past performance. The adjusted $R^{2}$, however, averages $29 \%$, suggesting that a large proportion of excess returns remains unexplained.

Interestingly, the time-series EW momentum portfolio (that considers all assets present in the cross section) generates a Sharpe ratio at 0.74 (Table 1, Panel A) which substantially exceeds that of the cross-sectional EW momentum portfolio (that merely shortlists the 10 assets with the most extreme characteristics; Sharpe ratio of 0.40, Appendix A). A comparison of the risk profiles of the two portfolios highlights the benefits of diversification obtained from holding all $N$ assets present at the time of portfolio formation, as opposed to merely the 10 most extreme performers. Likewise, the time-series EW momentum portfolio generates a positive alpha equal to $4.24 \%$ (t-statistic of 4.26) a year relative to the three-factor benchmark of Bakshi et al. (2017). These results highlight the superiority of the time-series, over cross-sectional, approach to portfolio construction.

Figure 1 presents the evolution in the aggregated long and short weights for each of the 11 strategies considered. The plots indicate strong similarities in the long-short splits across weighting schemes. For example, the correlations between any two pairs of aggregated long weights across strategies range from $40 \%$ (between VT and BT) to 1 (between NE and DA) with an average of $69 \%$. The darker (lighter) line on the right-hand side of each plot presents the future value of a $\$ 1$ investment into the momentum (AVG) portfolio. The plots provide a graphical endorsement of the MIN, VT, VaRT, and CVaRT strategies in terms of both reducing volatility and enhancing risk-adjusted returns. Interestingly, when commodity markets enter a correction (as portrayed by 
a drop in the value of the AVG investment), the MIN, VT, VaRT, and CVaRT portfolios seem to post interesting returns, suggesting that these strategies can partially hedge commodity risk.

[Figure 1 about here.]

Figure 1 also shows that PU, NE, DA, MV, and BT are the strategies that are the most sensitive to market movements; they often consist of either almost all long or almost all short positions. These near 100\% long or short weighting schemes imply that there shall be near perfect synchronicity in the phases of backwardation and contango across commodity markets; this does not occur in reality as at time $t$ the supply and demand conditions for, e.g., corn are unlikely to perfectly match those for, say, palladium. The observed extreme weights of the PU, NE, DA, MV, and BT strategies, and their lesser ability to time the specificities of each market, could explain why these strategies performed worse than the competing weighting schemes in Table 1.

All in all, we conclude that equal-weighting of the constituents of the momentum portfolio is suboptimal; enhanced risk-adjusted performance of the momentum strategy can be obtained by using weights based risk minimization (MIN) or risk timing (VT, VaRT, and CVaRT).

\subsection{Term structure-based strategies}

Are our results driven by the use of past performance as signal for allocation? To answer this question, we use roll-yield, in place of excess return, as sorting criterion for the backwardated and

contangoed portfolios. Table 2, Panel A presents summary statistics of performance for both the naive EW term structure portfolio and variants thereof based on optimized and risk-timing weights. Following the same format as Table 1, Panels B and C attempt to explain the excess returns of the sophisticated term structure strategies using either the excess returns of the naive EW term structure strategy in Panel B or the three-factor benchmark of Bakshi et al. (2017) in Panel C.

[Table 2 about here.]

Three sophisticated term structure strategies, those based on MIN, RRT, and BT weights, stand out as outperforming the standard EW term structure portfolio. This is evidenced by Sharpe, Sortino and Omega ratios that are higher for these sophisticated strategies and lower for the naive 
portfolio and by positive and statistically significant alphas in both Panels B and C (the annualized alphas range from $1.50 \%$ (MIN) to $8.75 \%(B T)$ ). The outperformance of MIN, RRT, and BT relative to EW is driven either by notably higher mean excess returns (RRT and BT) or by substantially more appealing risk measures (MIN).

At the other end of the spectrum, the term structure portfolios based on utility maximization (namely, PU, NE, DA, and MV) stand out again as being the least profitable; they present Sharpe ratios that merely equal 0.32 on average (versus 0.58 for EW) and alphas that are statistically insignificant in both panels B and C. As expected (Jagannathan and Ma, 2003; Michaud, 2008; Kirby and Ostdiek, 2012; Low et al., 2016), a detailed non-reported analysis of these asset allocations indicates extreme weights and poor diversification.

Figure 2 plots the evolution over time of the aggregated long and short allocations of the various term structure portfolios, alongside the future value of a $\$ 1$ investment in the AVG and term structure portfolios. Like for momentum before, we note a tendency for the aggregated long weights to move in tandem across weighting schemes; and likewise for the aggregated short weights. The figure also confirms conclusions drawn previously. For example, panel (f) shows that MIN is a strategy with a positive and smooth performance, while panels (h) and (i) highlight that the superiority of the RRT and BT strategies in terms of performance comes at the price of relatively high levels of risk.

[Figure 2 about here.]

A comparison of the risk and performance measures obtained in Tables 1 and 2 shows that the profitability of a strategy depends more on the weighting scheme chosen than on the criterion used to sort the cross section into backwardation and contango. Irrespective of the signal employed, weighting schemes that either minimize or time risk are indeed found to beat the equal-weight benchmarks. On the other hand, weighting schemes based on utility maximization lead to poorly diversified portfolios with meagre risk-adjusted performance compared to EW. 


\section{Robustness checks}

The conclusion thus far is that the risk-minimization and risk-timing schemes when applied to the popular EW momentum and term structure strategies generate enhanced risk-adjusted performance. This section tests the robustness of this conclusion to considerations pertaining to transaction costs, illiquidity, model parameters and sub-periods.

\subsection{Turnover and transaction costs}

As transaction costs can erode the profits of otherwise lucrative strategies (Do and Faff, 2012), we measure the turnover and net performance of the various momentum and term structure strategies relative to three sets of transaction costs. These include the costs of opening and closing positions as contracts enter or exit the portfolios, the costs of rolling contracts forward as they come close to maturity and; finally, the costs of rebalancing existing positions to their desired weights at the end of each holding period.

Following DeMiguel et al. (2009), we measure the monthly turnover (TO) of each strategy as the average of all trades

$$
T O=\frac{1}{T-1} \sum_{t=1}^{T-1} \sum_{i=1}^{N}\left(\left|x_{i, t+1}-x_{i, t^{+}}\right|\right),
$$

$x_{i, t^{+}}$and $x_{i, t+1}$ are the weights assigned to the $i^{t h}$ futures at the end of month $t+1$ before and after portfolio rebalancing, respectively; thus our definition of turnover takes into account the fact that portfolio weights naturally evolve with the performance of the assets. $T$ is the number of observations in the holding period of the portfolios and $N$ is the number of commodity futures present in the cross section at each month end. The turnover ranges from 0 (when no trading occurs) to 2 (when all existing positions are closed and $N$ new positions are subsequently opened).

Net returns are then calculated as

$$
r_{p, t+1}=\sum_{i=1}^{N} x_{i, t} r_{i, t+1}-\sum_{i=1}^{N} T C \times\left|x_{i, t+1}-x_{i, t^{+}}\right|
$$

Following Marshall et al. (2012), we assume a conservative level of transaction costs (TC) of 8.6 b.p. It is worth noting that there are no short selling restrictions in futures markets and thus, 
long and short positions cost the same.

Table 3 reports the results of our transaction costs analysis for the momentum strategies in Panel A and for the term structure strategies in Panel B. It is clear that the use of a sophisticated weighting scheme has little impact on turnover and transaction costs. The momentum and term structure strategies that outperformed their equal-weight counterparts in Table 1 (MIN, VT, VaRT, and CVaRT) and Table 2 (MIN, RRT, and BT) still offer superior net Sharpe ratios in Table 3. In other words, the ranking of performance is unchanged and the conclusions drawn thus far are robust to the consideration of transaction costs.

[Table 3 about here.]

\subsection{Liquidity risk}

As further robustness checks, we test whether the performance identified in Tables 1 and 2 is merely driven by the lack of liquidity of the constituents traded in the long-short portfolios. To do so, we conduct two tests. First, we remove from the cross section available at the time of portfolio formation the $10 \%$ of contracts that have the lowest Amivest measure (namely, those with the lowest \$Volume per unit of absolute return as averaged over the past two months) and implement the strategies on the remaining $90 \%$. If lack of liquidity drives part of the performance, the strategies that trade the most liquid assets shall exhibit a performance that is noticeably worse than that reported in Tables 1 and 2. Second, we measure the alpha of the naive and sophisticated strategies relative to the three-factor model of Bakshi et al. (2017), augmented with a risk premium based on Amihud et al. (1997) liquidity measure.

The results are reported in Table 4. Using a smaller cross section of liquid assets has no bearing on relative performance. Besides, the measures of abnormal performance are of a similar magnitude as previously reported in Tables 1 and 2, Panels $\mathrm{C}$ and the exposures of the strategies to the liquidity risk premium are often equal to zero at the $5 \%$ level. We conclude therefore that the outperformance of the MIN, VT, VaRT, and CVaRT momentum strategies and that of the MIN, RRT, and BT term structure strategies relative to their naive counterparts are not merely a compensation for liquidity risk. 
[Table 4 about here.]

\subsection{Choice of model parameters}

Our base-case assumes an estimation period of 12 months for the portfolio weights, a 12-month ranking period for momentum, a 1-month holding period, and a tuning parameter $\eta$ equal to 1 . Table 5 allays concerns regarding the sensitivity of our results to these choices by considering three weighting ranking periods $\left(R_{\text {weight }}\right)$ set to 3,6 , or 18 months, ${ }^{10}$ two momentum ranking $\operatorname{periods}\left(R_{\text {mom }}\right)$ set to 3 and 6 , two holding periods $(H)$ set to 2 and 4 months, and two tuning parameters $(\eta)$ set to 2 and 3. The conclusions are mostly unchanged. With only a few exceptions, the sophisticated momentum and term structure strategies that outperform their equal-weight counterparts are the same under these alternative settings as those in Tables 1 and 2. The exceptions pertain, for example, to term structure portfolios with a holding period of 4 months and to VT momentum strategies with tuning parameters $\eta$ exceeding 1.

[Table 5 about here.]

\subsection{Sub-sample analysis}

We appraise the performance of the strategies over various sub-periods. These are delimited as follows: pre and post financialization (dated January 2006, Stoll and Whaley, 2011); periods of heightened versus reduced conditional volatility in commodity (or equity) markets (where the threshold is defined as the long-term average S\&P-GSCI (S\&P500) volatility estimated from a GARCH(1,1) model), as well as over five consecutive periods of roughly equal lengths. The conclusions presented in Table 6, Panel A for the momentum strategies are remarkably consistent with those reported in Table 1: irrespective of the sample considered, the Sharpe ratios of the MIN, VT, VaRT, and CVaRT exceed those of EW. The inferences presented in Table 6, Panel B for the term structure strategies are slightly less robust. As in Table 2, MIN and RRT nearly always generate higher Sharpe ratios that EW but that conclusion applies less often to BT. Interestingly, the strategies perform better in period of low volatility in commodity and equity markets, suggesting that the timing strategies of Barroso and Santa-Clara (2015) could enhance performance further.

\footnotetext{
${ }^{10}$ The use of a longer estimation period shall mitigate legitimate concerns regarding estimation errors.
} 
[Table 6 about here.]

\section{Conclusions}

This article introduces a new long-short portfolio construction technique that simultaneously captures the fundamentals of backwardation and contango present in commodity futures markets and allows for weighting schemes that depart from the traditional naive weights. These sophisticated weighting schemes emanate from the optimization and risk-timing literatures as thus far applied to the construction of long-only equity portfolios. By comparing the performance of the sophisticated long-short momentum and term structure strategies to that of their naive equal-weight counterparts, this article tests whether sophistication in the weighting scheme has bearing on performance.

The empirical results show that the equal-weight scheme that is traditionally employed in the construction of long-short portfolios is quite easy to beat. Momentum and term structure portfolios that use weights that minimize or time risk yield more than the naive equal-weight portfolios. At the other end of the spectrum, weighting schemes based on utility maximization lead to poorly diversified portfolios with meagre risk-adjusted performance. These conclusions persist after accounting for the risks of the strategies as captured by the now traditional commodity pricing model of Bakshi et al. (2017) and are broadly unaltered by the consideration of transaction costs, lack of liquidity, various model specifications or different sub-periods. By showing that long-short

allocations based on risk timing outperform long-short allocations based on equal weights, our article extends to a long-short setting the conclusions that Kirby and Ostdiek (2012) drew in a long-only context.

Focusing exclusively on momentum and term structure, we show that sophistication in the weighting scheme can generate added performance relative to the naive weights typically employed. Other strategies (based on e.g., skewness, value, volatility, liquidity) have been shown to work well in commodity futures markets. It remains to be tested whether the equal-weighting scheme then applied is optimal. We hope that our analysis will instigate further research in this regard. 


\section{References}

Amihud, Y., Mendelson, H., Lauterbach, B., 1997. Market microstructure and securities values: evidence from the Tel Aviv Stock Exchange. Journal of Financial Economics 45 (3), 365-390.

Artzner, P., Delbaen, F., Eber, J.-M., Heath, D., 1999. Coherent measures of risk. Mathematical Finance 9 (3), 203-228.

Asness, C. S., Moskowitz, T. J., Pedersen, L. H., 2013. Value and momentum everywhere. Journal of Finance 68 (3), 929-985.

Bakshi, G., Gao, X., Rossi, A. G., 2017. Understanding the sources of risk underlying the cross section of commodity returns. Management Science, forthcoming.

Barroso, P., Santa-Clara, P., 2015. Momentum has its moments. Journal of Financial Economics $116(1), 111-120$.

Basu, D., Miffre, J., 2013. Capturing the risk premium of commodity futures: the role of hedging pressure. Journal of Banking \& Finance 37 (7), 2652-2664.

Bessembinder, H., 1992. Systematic risk, hedging pressure, and risk premiums in futures markets. Review of Financial Studies 5 (4), 637-667.

Cootner, P. H., 1960. Returns to speculators: Telser versus Keynes. Journal of Political Economy $68(4), 396-404$.

De Roon, F. A., Nijman, T. E., Veld, C., 2000. Hedging pressure effects in futures markets. Journal of Finance 55 (3), 1437-1456.

DeMiguel, V., Garlappi, L., Uppal, R., 2009. Optimal versus naive diversification: how inefficient is the 1/N portfolio strategy? Review of Financial Studies 22 (5), 1915-1953.

Do, B., Faff, R., 2012. Are pairs trading profits robust to trading costs? Journal of Financial Research 35 (2), 261-287. 
Erb, C. B., Harvey, C. R., 2006. The strategic and tactical value of commodity futures. Financial Analysts Journal 62 (2), 69-97.

Fama, E. F., French, K. R., 1987. Commodity futures prices: some evidence on forecast power, premiums, and the Theory of Storage. Journal of Business 60 (1), 55-73.

Fernandez-Perez, A., Frijns, B., Fuertes, A.-M., Miffre, J., 2018. The skewness of commodity futures returns. Journal of Banking \& Finance 86, 143-158.

Fletcher, J., 2011. Do optimal diversification strategies outperform the 1/N strategy in U.K. stock returns? International Review of Financial Analysis 20 (5), 375-385.

Gorton, G., Rouwenhorst, K. G., 2006. Facts and fantasies about commodity futures. Financial Analysts Journal 62 (2), 47-68.

Gorton, G. B., Hayashi, F., Rouwenhorst, K. G., 2013. The fundamentals of commodity futures returns. Review of Finance 17 (1), 35-105.

Gul, F., 1991. A theory of disappointment aversion. Econometrica 59 (3), 667-686.

Hong, H., Yogo, M., 2012. What does futures market interest tell us about the macroeconomy and asset prices? Journal of Financial Economics 105 (3), 473-490.

Jagannathan, R., Ma, T., 2003. Risk reduction in large portfolios: why Imposing the wrong constraints helps. Journal of Finance 58 (4), 1651-1683.

Kaldor, N., 1939. Speculation and economic stability. Review of Economic Studies 7 (1), 1-27.

Kirby, C., Ostdiek, B., 2012. Its all in the timing: simple active portfolio strategies that outperform naive diversification. Journal of Financial and Quantitative Analysis 47 (02), 437-467.

Kolm, P. N., Ttnc, R., Fabozzi, F. J., 2014. 60 years of portfolio optimization: practical challenges and current trends. European Journal of Operational Research 234 (2), 356-371. 
Low, R. K. Y., Alcock, J., Faff, R., Brailsford, T., 2013. Canonical vine copulas in the context of modern portfolio management: are they worth it? Journal of Banking \& Finance 37 (8), 3085-3099.

Low, R. K. Y., Faff, R., Aas, K., 2016. Enhancing meanvariance portfolio selection by modeling distributional asymmetries. Journal of Economics and Business 85, 49-72.

Markowitz, H., 1952. Portfolio selection. Journal of Finance 7 (1), 77-91.

Marshall, B. R., Nguyen, N. H., Visaltanachoti, N., 2012. Commodity liquidity measurement and transaction costs. Review of Financial Studies 25 (2), 599-638.

Merton, R. C., 1980. On estimating the expected return on the market: an exploratory investigation. Journal of Financial Economics 8 (4), 323-361.

Michaud, R. O., 2008. Efficient asset management: a practical guide to stock portfolio optimization and asset allocation. OUP Catalogue. Oxford University Press.

Miffre, J., 2016. Long-short commodity investing: A review of the literature. Journal of Commodity Markets 1 (1), 3-13.

Miffre, J., Rallis, G., 2007. Momentum strategies in commodity futures markets. Journal of Banking \& Finance 31 (6), 1863-1886.

Moskowitz, T. J., Ooi, Y. H., Pedersen, L. H., 2012. Time series momentum. Journal of Financial Economics 104 (2), 228-250.

Rockafellar, R. T., Uryasev, S., 2002. Conditional Value-at-Risk for general loss distributions. Journal of Banking \& Finance 26 (7), 1443-1471.

Stoll, H. R., Whaley, R. E., 2011. Commodity index investing: speculation or diversification? Journal of Alternative Investments 14 (1), 50-60,8-9.

Symeonidis, L., Prokopczuk, M., Brooks, C., Lazar, E., 2012. Futures basis, inventory and commodity price volatility: An empirical analysis. Economic Modelling 29 (6), 2651-2663. 
Szakmary, A. C., Shen, Q., Sharma, S. C., 2010. Trend-following trading strategies in commodity futures: a re-examination. Journal of Banking \& Finance 34 (2), 409-426.

Szymanowska, M., De Roon, F., Nijman, T., Van Den Goorbergh, R., 2014. An anatomy of commodity futures risk premia. Journal of Finance 69 (1), 453-482.

Tu, J., Zhou, G., 2011. Markowitz meets Talmud: a combination of sophisticated and naive diversification strategies. Journal of Financial Economics 99 (1), 204-215. 


\section{Appendix A. Summary statistics for the risk factors}

The table presents summary statistics for the excess returns of long-only and long-short portfolios. AVG is a longonly equally-weighted monthly-rebalanced portfolio of all commodity futures, CARRY, MOM and LIQ are equallyweighted monthly-rebalanced long-short portfolios based on roll-yields, past performance and liquidity ratios, respectively. Mean, volatility and downside volatility (relative to a zero excess return) have been annualized, significance t-ratios for the annualized mean excess returns are shown in parentheses. Bold fonts denote significance at the $5 \%$ level or better. Sharpe (Sortino) ratios are Mean over Volatility (Downside volatility using 0\% as threshold). Omega ratios are the probability of gains divided by the probability of losses using $0 \%$ as threshold. The analysis spans the sample January 1980 to April 2016.

\begin{tabular}{|c|c|c|c|c|c|}
\hline & \multicolumn{2}{|c|}{ Long-only portfolios } & \multicolumn{3}{|c|}{ Long-short portfolios } \\
\hline & AVG & S\&P-GSCI & CARRY & $\mathrm{MOM}$ & LIQ \\
\hline Mean & 0.0169 & $\begin{array}{l}0.0341 \\
(-083)\end{array}$ & $\mathbf{0 . 0 6 5 2}$ & 0.0520 & $\mathbf{0 . 0 5 6 9}$ \\
\hline Volatility & 0.12 & $\begin{array}{c}-0.00) \\
0.20\end{array}$ & 0.12 & 0.13 & 0.11 \\
\hline Downside volatility & 0.09 & 0.14 & 0.08 & 0.08 & 0.06 \\
\hline Skewness & -0.61 & -0.31 & -0.20 & -0.05 & 0.36 \\
\hline Ex. kurtosis & 2.88 & 2.24 & 2.82 & 0.75 & 0.93 \\
\hline JB p.value & 0.00 & 0.00 & 0.00 & 0.00 & 0.00 \\
\hline $\operatorname{VaR}(95 \%)$ & -0.05 & -0.10 & -0.05 & -0.06 & -0.04 \\
\hline CVaR $(95 \%)$ & -0.08 & -0.13 & -0.07 & -0.08 & -0.06 \\
\hline Max drawdown & 0.31 & 0.52 & 0.27 & 0.27 & 0.22 \\
\hline Sharpe ratio & 0.14 & 0.17 & 0.57 & 0.40 & 0.53 \\
\hline Sortino ratio & 0.19 & 0.24 & 0.83 & 0.64 & 0.96 \\
\hline Omega ratio & 1.11 & 1.14 & 1.56 & 1.35 & 1.51 \\
\hline
\end{tabular}


Figure 1: Aggregated long and short momentum allocations

This figure shows the evolution of the aggregated long and short positions of the momentum strategies. The dark (light) area on each graph represents the sum of the long (short) weights. The dark (light) line represents the future value of $\$ 1$ invested in the momentum (AVG) portfolio, where AVG is a long-only equally-weighted monthlyrebalanced portfolio of all commodity futures. EW stands for equal weights. PU, NE, DA, MV, and MIN stand for power utility, negative exponential utility, power utility with disappointment aversion, mean variance, and minimum variance, respectively. VT, RRT, BT, VaRT, and CVaRT stand for volatility timing, reward-to-risk timing, betatiming, Value-at-Risk timing, and Conditional Value-at-Risk timing, respectively.

(a) $\mathrm{EW}$

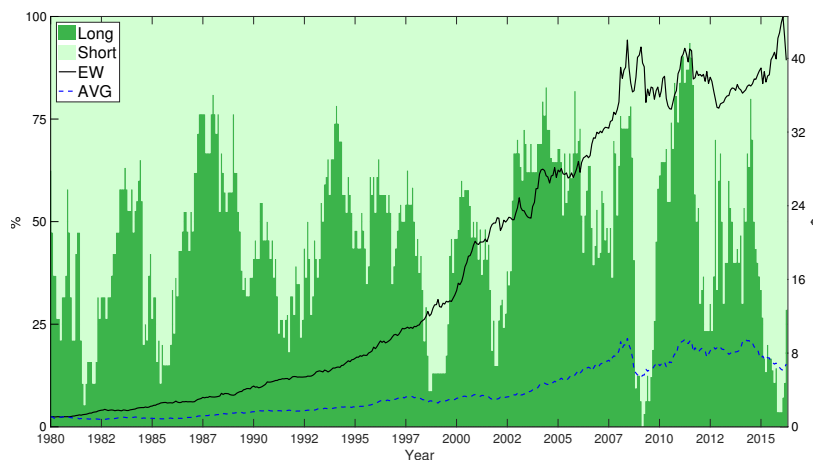

(c) $\mathrm{NE}$

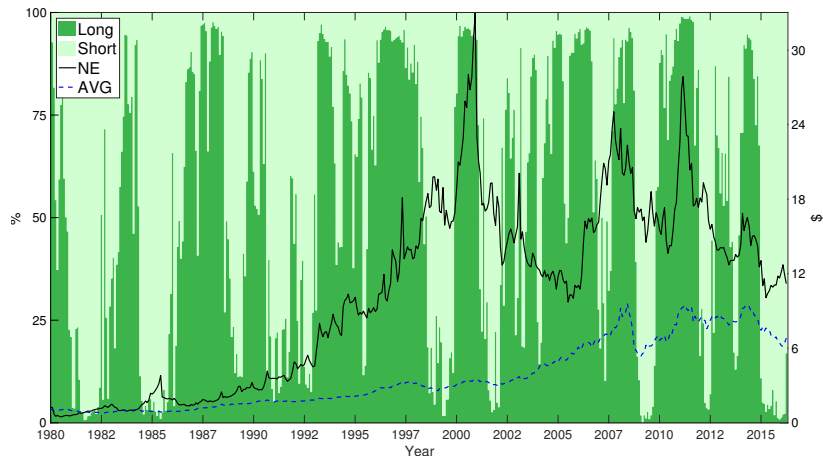

(e) MV

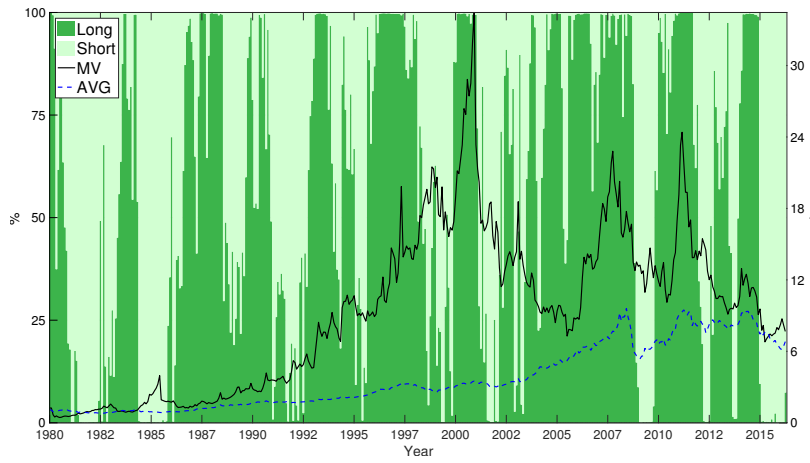

(g) VT

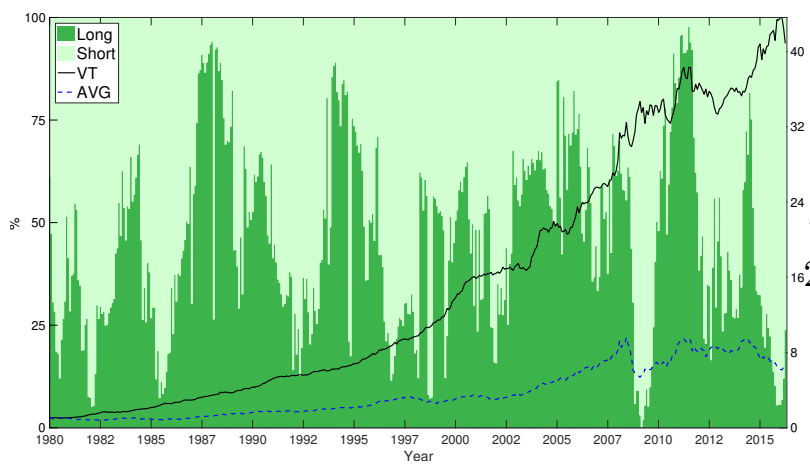

(b) PU

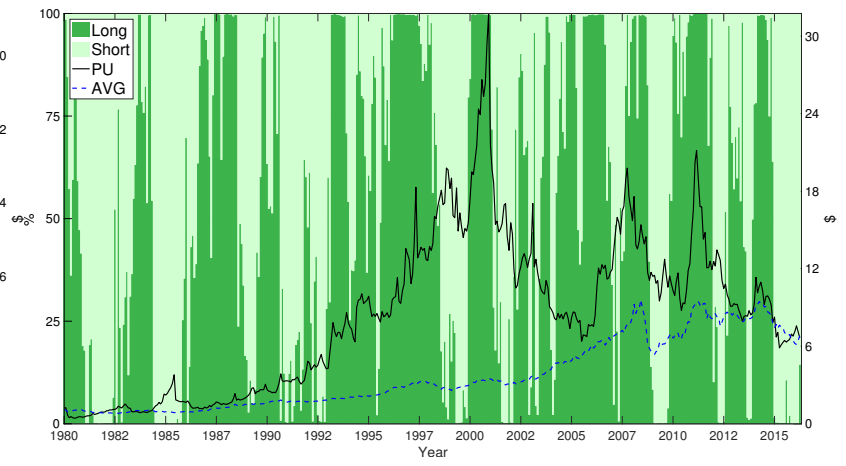

(d) DA

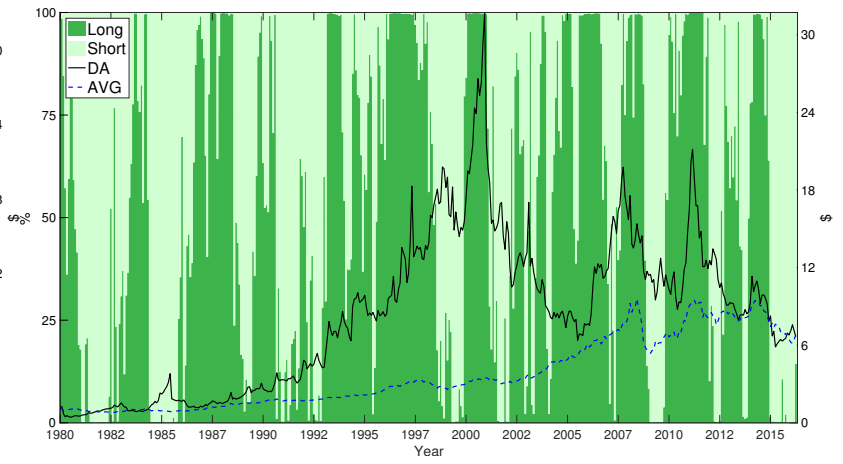

(f) $\mathrm{MIN}$

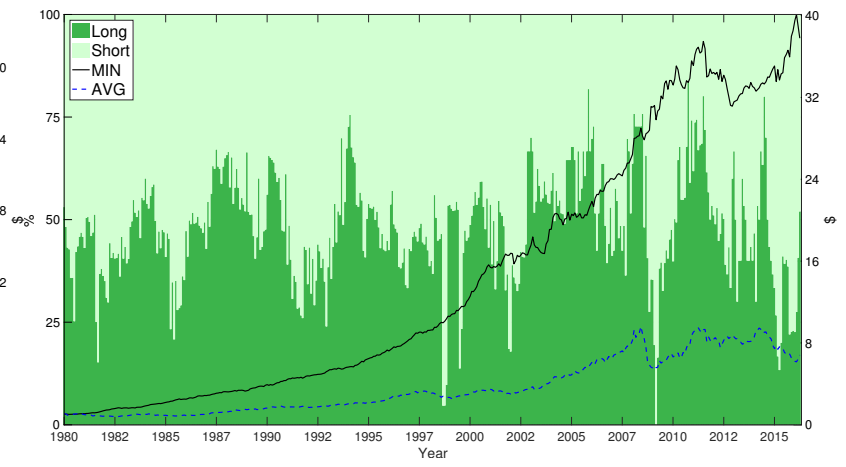

(h) RRT

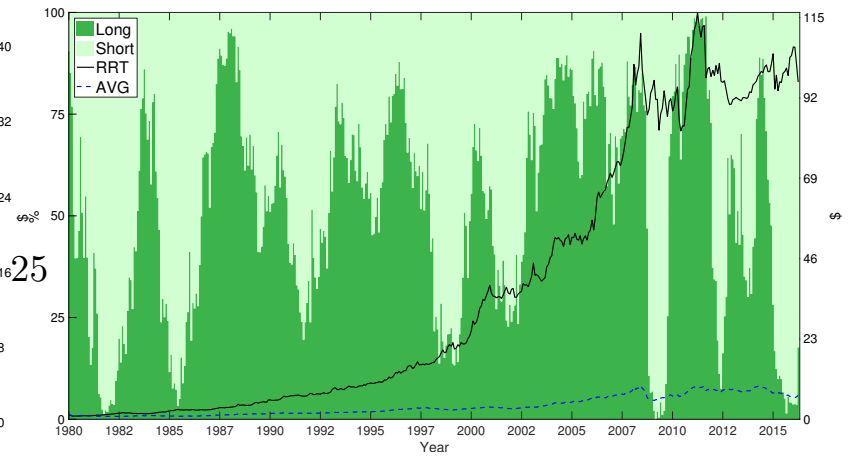


(i) $\mathrm{BT}$

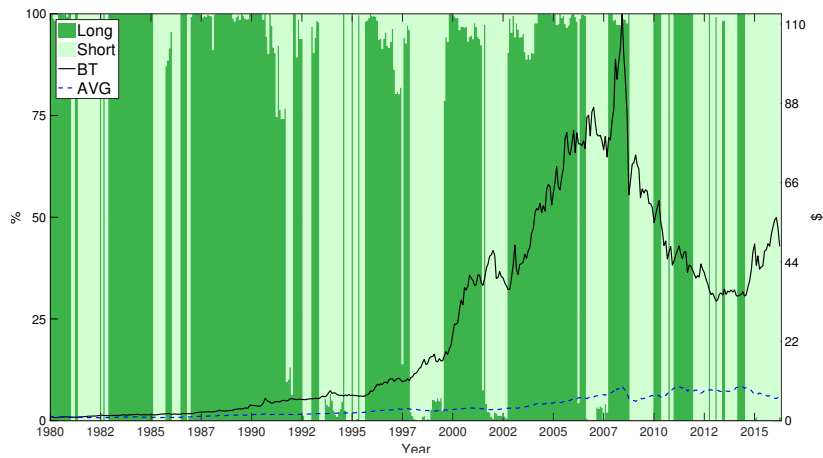

(j) VaRT

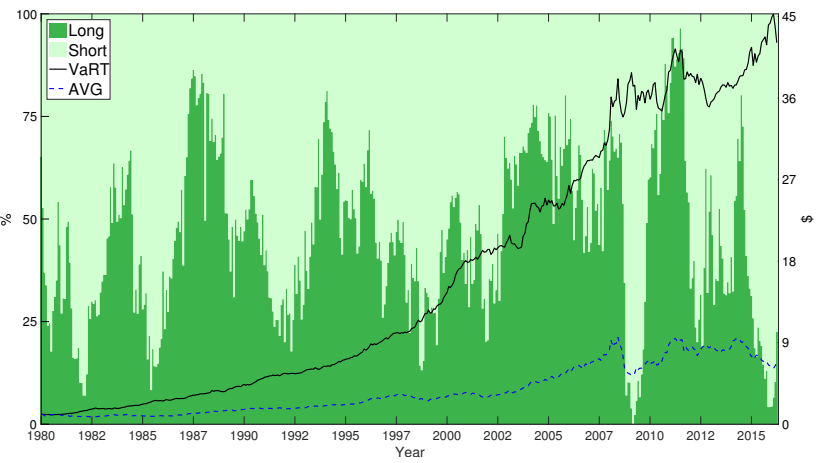

(k) CVaRT

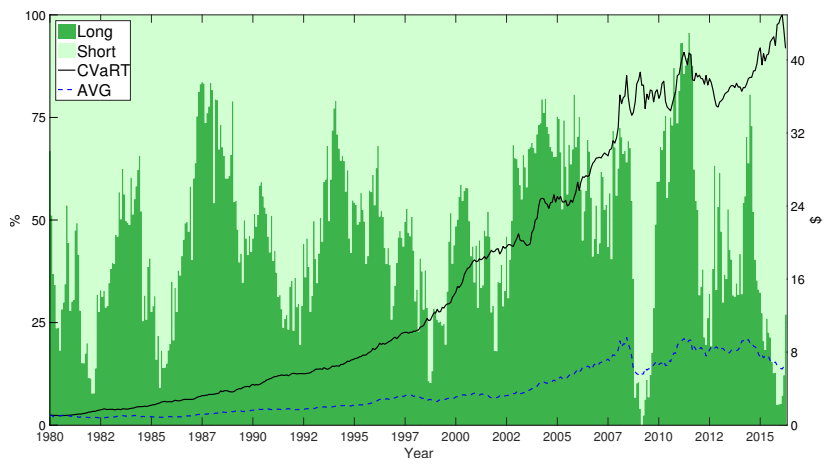


Figure 2: Aggregated long and short term structure allocations

This figure shows the evolution of the aggregated long and short positions of the term structure strategies. The dark (light) area on each graph represents the sum of the long (short) weights. The dark (light) line represents the future value of $\$ 1$ invested in the term structure (AVG) portfolio, where AVG is a long-only equally-weighted monthly-rebalanced portfolio of all commodity futures. EW stands for equal weights. PU, NE, DA, MV, and MIN stand for power utility, negative exponential utility, power utility with disappointment aversion, mean variance, and minimum variance, respectively. VT, RRT, BT, VaRT, and CVaRT stand for volatility timing, reward-to-risk timing, beta-timing, Value-at-Risk timing, and Conditional Value-at-Risk timing, respectively.

(a) EW

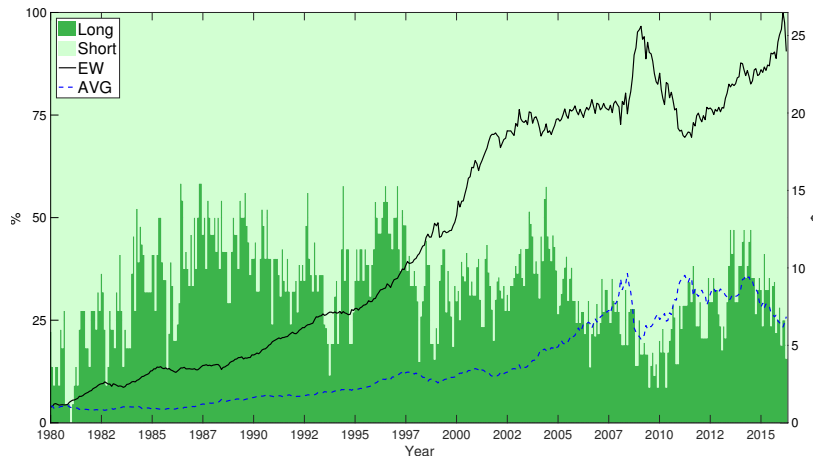

(c) $\mathrm{NE}$

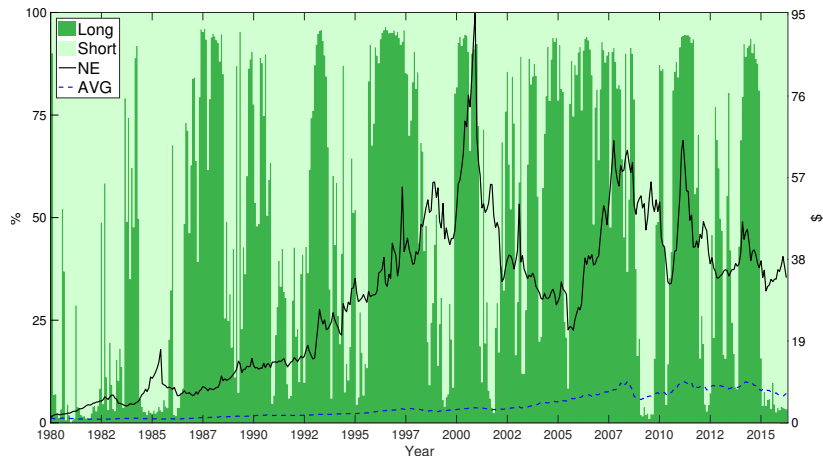

(e) MV

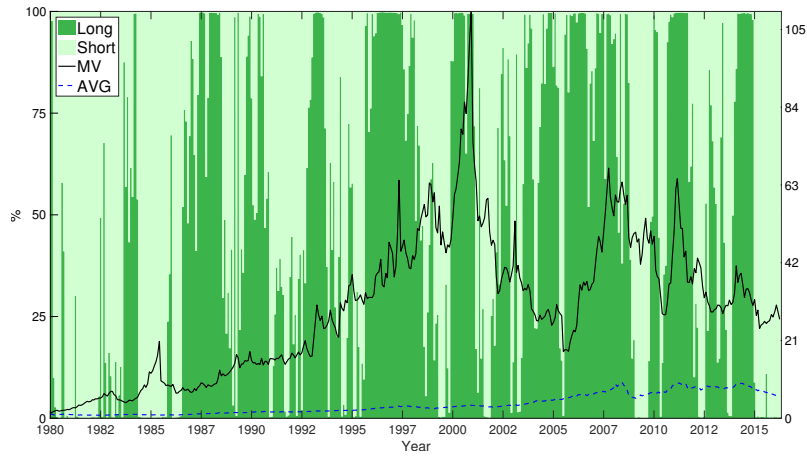

(g) VT

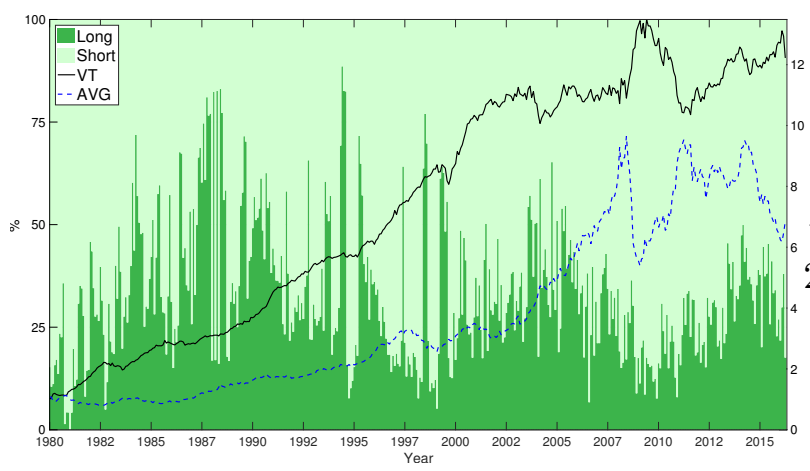

(b) PU

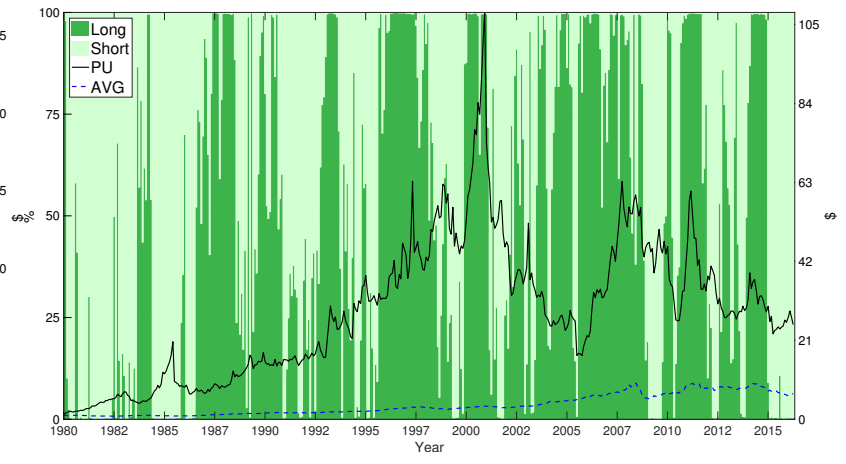

(d) DA

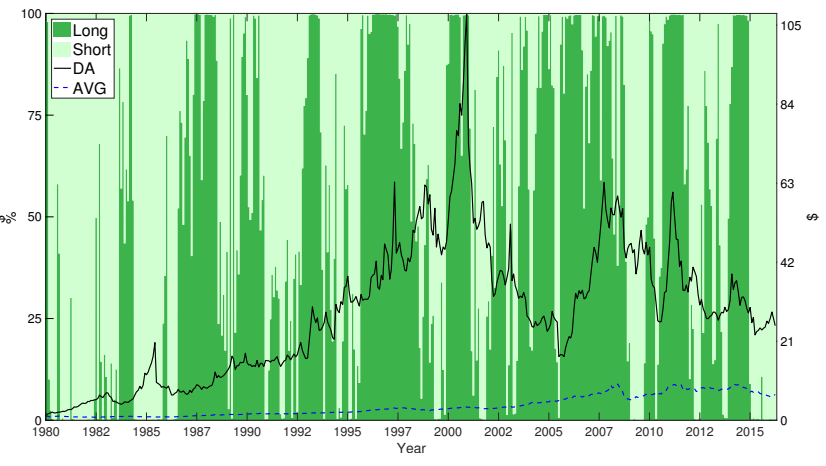

(f) $\mathrm{MIN}$

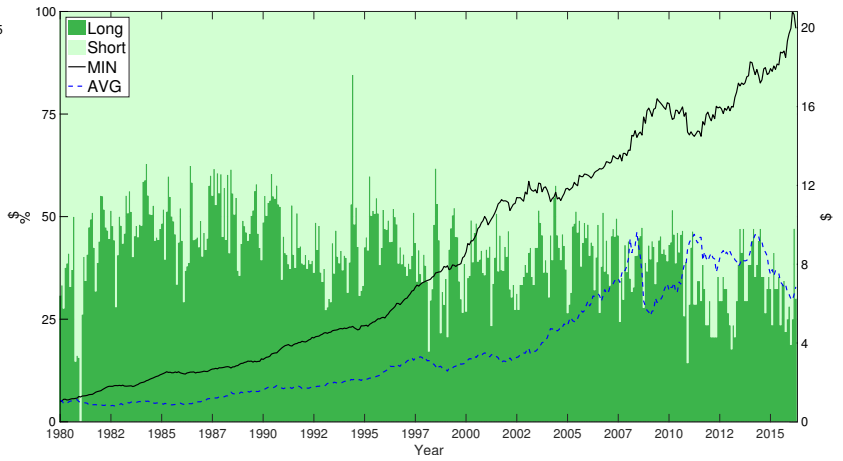

(h) RRT

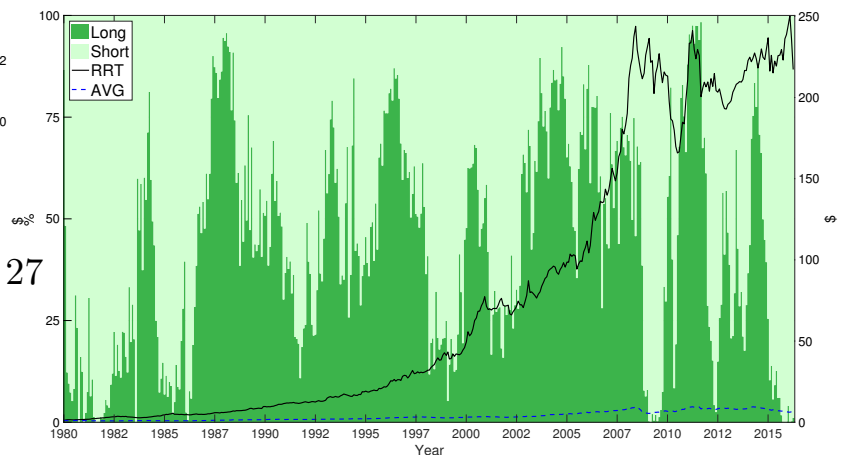


(i) $\mathrm{BT}$

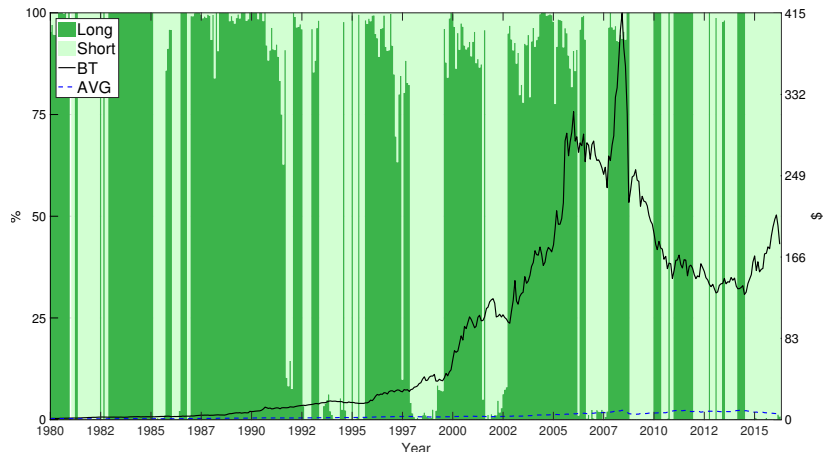

(j) VaRT

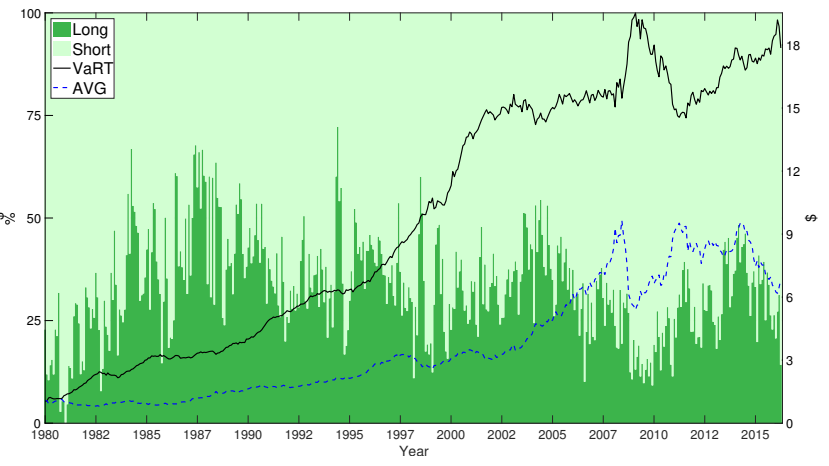

(k) CVaRT

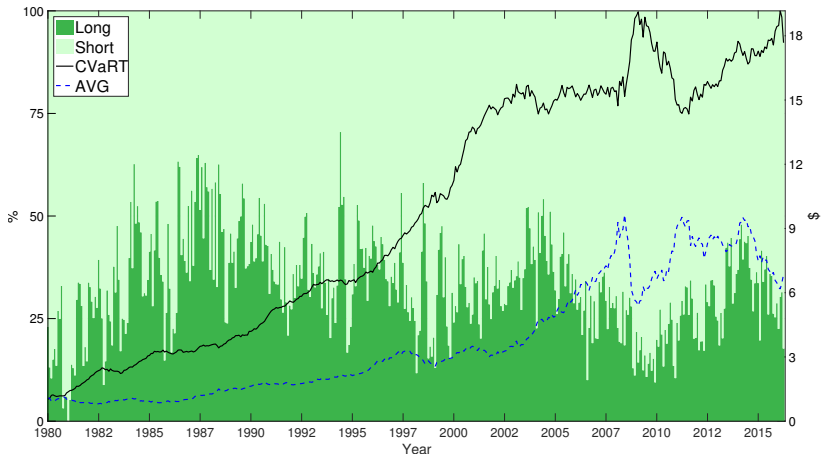


Table 1: Risk and performance of momentum portfolios under various weighting schemes

Panel A presents summary statistics for the excess returns of long-short momentum portfolios under various weighting schemes. Panels B and C report parameter estimates, Newey-West t-statistics and adjusted $R^{2}$ obtained from regressions of the excess returns of a given naive or sophisticated strategy on the excess returns of the relevant risk factors. PU, NE, DA, MV, and MIN stand for power utility, negative exponential utility, power utility with disappointment aversion, mean variance utility, and minimum variance, respectively. VT, RRT, BT, VaRT and CVaRT stand for volatility timing, reward-to-risk timing, beta-timing, Value-at-Risk timing, and Conditional Valueat-Risk timing, respectively. Mean, volatility, downside volatility (relative to a zero excess return) and abnormal returns $(\alpha)$ have been annualized, Newey-West t-ratios are shown in parentheses, t-statistics for the null hypothesis that a given sophisticated strategy generates the same mean excess return as its equal-weight counterpart are reported under the heading "ew tstat". Bold fonts denote significance at the $5 \%$ level or better. Sharpe (Sortino) ratios are mean over volatility (downside volatility using $0 \%$ as threshold). Omega ratios are the probability of gains divided by the probability of losses using $0 \%$ as threshold. AVG is a long-only equally-weighted monthly-rebalanced portfolio of all commodity futures, CARRY and MOM are equally-weighted monthly-rebalanced long-short portfolios based on roll-yields and past performance, respectively. The analysis spans the sample January 1980 to April 2016.

\begin{tabular}{|c|c|c|c|c|c|c|c|c|c|c|c|}
\hline & \multirow{2}{*}{$\begin{array}{c}\text { Equal } \\
\text { Weights }\end{array}$} & \multicolumn{5}{|c|}{ Optimized weights } & \multicolumn{5}{|c|}{ Risk-timing weights } \\
\hline & & $\mathrm{PU}$ & $\mathrm{NE}$ & DA & $\mathrm{MV}$ & MIN & VT & RRT & $\mathrm{BT}$ & VaRT & CVaRT \\
\hline \multicolumn{12}{|c|}{ Panel A: Summary statistics } \\
\hline Mean & 0.0619 & 0.0749 & 0.0739 & 0.0749 & 0.0779 & 0.0588 & 0.0612 & 0.0919 & 0.0813 & 0.0625 & 0.0620 \\
\hline tstat & $(3.80)$ & $(1.06)$ & $(1.22)$ & $(1.06)$ & $(1.35)$ & $(4.23)$ & $(4.04)$ & $(3.55)$ & $(2.39)$ & $(4.06)$ & $(4.08)$ \\
\hline ew tstat & $(0.00)$ & $(-0.24)$ & $(-0.26)$ & $(-0.24)$ & $(-0.30)$ & $(0.38)$ & $(0.08)$ & $(-2.33)$ & $(-0.79)$ & $(-0.13)$ & $(-0.01)$ \\
\hline Volatility & 0.08 & 0.35 & 0.31 & 0.35 & 0.35 & 0.06 & 0.06 & 0.13 & 0.19 & 0.07 & 0.07 \\
\hline Downside volatility & 0.06 & 0.25 & 0.23 & 0.25 & 0.25 & 0.04 & 0.04 & 0.10 & 0.13 & 0.05 & 0.05 \\
\hline Skewness & -0.22 & -0.35 & -0.46 & -0.35 & -0.34 & -0.07 & 0.12 & -0.57 & -0.17 & -0.03 & 0.01 \\
\hline Ex. kurtosis & 1.64 & 3.40 & 4.00 & 3.40 & 3.38 & 2.37 & 2.13 & 4.82 & 2.75 & 2.22 & 2.07 \\
\hline JB p.value & 0.00 & 0.00 & 0.00 & 0.00 & 0.00 & 0.00 & 0.00 & 0.00 & 0.00 & 0.00 & 0.00 \\
\hline $\operatorname{VaR}(95 \%)$ & -0.04 & -0.16 & -0.13 & -0.16 & -0.16 & -0.02 & -0.03 & -0.05 & -0.08 & -0.03 & -0.03 \\
\hline CVaR (95\%) & -0.05 & -0.24 & -0.21 & -0.24 & -0.23 & -0.03 & -0.04 & -0.08 & -0.12 & -0.04 & -0.04 \\
\hline Max drawdown & 0.20 & 0.86 & 0.77 & 0.86 & 0.86 & 0.16 & 0.17 & 0.40 & 0.50 & 0.18 & 0.18 \\
\hline Sharpe ratio & 0.74 & 0.21 & 0.24 & 0.21 & 0.22 & 0.97 & 0.95 & 0.69 & 0.44 & 0.87 & 0.87 \\
\hline Sortino ratio & 1.08 & 0.29 & 0.32 & 0.29 & 0.31 & 1.45 & 1.50 & 0.92 & 0.63 & 1.31 & 1.34 \\
\hline Omega ratio & 1.76 & 1.18 & 1.21 & 1.18 & 1.19 & 2.12 & 2.06 & 1.73 & 1.40 & 1.95 & 1.94 \\
\hline \multicolumn{12}{|c|}{ Panel B: Regression analysis relative to the equal-weight benchmark } \\
\hline & & $\begin{array}{c}-0.0560 \\
(-1.09)\end{array}$ & $\begin{array}{c}-0.0490 \\
(-1.11)\end{array}$ & $\begin{array}{c}-0.0560 \\
(-1.09)\end{array}$ & $\begin{array}{c}-0.0524 \\
(-1.03)\end{array}$ & $\begin{array}{c}\mathbf{0 . 0 2 2 9} \\
(2.98)\end{array}$ & $\begin{array}{c}\mathbf{0 . 0 2 3 6} \\
(3.26)\end{array}$ & $\begin{array}{c}0.0099 \\
(0.84)\end{array}$ & $\begin{array}{c}-0.0083 \\
(-0.36)\end{array}$ & $\begin{array}{c}\mathbf{0 . 0 1 2 6} \\
(2.98)\end{array}$ & $\begin{array}{c}\mathbf{0 . 0 1 2 1} \\
(2.91)\end{array}$ \\
\hline$\beta$ & & 2.11 & 1.99 & 2.11 & 2.10 & $\mathbf{0 . 5 8}$ & $\mathbf{0 . 6 1}$ & 1.32 & $\begin{array}{c}1.45 \\
(14.22)\end{array}$ & $\begin{array}{c}\mathbf{0 . 8 1} \\
(33.91)\end{array}$ & $\mathbf{0 . 8 1}$ \\
\hline Adj. $R^{2}$ & & $\begin{array}{c}(8.45) \\
0.25\end{array}$ & $\begin{array}{c}(8.99) \\
0.28\end{array}$ & $\begin{array}{c}(8.45) \\
0.25\end{array}$ & $\begin{array}{c}(8.48) \\
0.25\end{array}$ & $\begin{array}{c}(11.96) \\
0.65\end{array}$ & $\begin{array}{c}(15.66) \\
0.61\end{array}$ & $\begin{array}{c}(19.01) \\
0.70\end{array}$ & $\begin{array}{c}(14.22) \\
0.42\end{array}$ & $\begin{array}{c}(33.91) \\
0.89\end{array}$ & $\begin{array}{c}(35.60) \\
0.89\end{array}$ \\
\hline \multicolumn{12}{|c|}{ Panel C: Regression analysis relative to the Bakshi et al. (2017) benchmark } \\
\hline$\alpha$ & $\begin{array}{c}\mathbf{0 . 0 4 2 4} \\
(4.26)\end{array}$ & $\begin{array}{c}-0.0219 \\
(-0.40)\end{array}$ & $\begin{array}{c}-0.0135 \\
(-0.28)\end{array}$ & $\begin{array}{c}-0.0219 \\
(-0.40)\end{array}$ & $\begin{array}{c}-0.0182 \\
(-0.33)\end{array}$ & $\begin{array}{c}\mathbf{0 . 0 4 4 0} \\
(5.39)\end{array}$ & $\underset{(5.41)}{\mathbf{0 . 0 5 3 0}}$ & $\begin{array}{c}\mathbf{0 . 0 5 3 5} \\
(3.34)\end{array}$ & $\begin{array}{c}0.0412 \\
(1.47)\end{array}$ & $\begin{array}{c}\mathbf{0 . 0 4 8 9} \\
(5.31)\end{array}$ & $\begin{array}{c}\mathbf{0 . 0 4 8 4} \\
(5.30)\end{array}$ \\
\hline$\beta_{A V G}$ & 0.00 & 0.39 & 0.35 & 0.39 & 0.38 & 0.01 & 0.01 & 0.20 & 0.31 & 0.02 & 0.01 \\
\hline & $(0.01)$ & $(2.15)$ & $(2.19)$ & $(2.15)$ & $(2.12)$ & $(0.17)$ & $(0.14)$ & $(2.05)$ & $(1.95)$ & $(0.25)$ & $(0.16)$ \\
\hline$\beta_{C A R R Y}$ & $\begin{array}{c}-0.01 \\
(-0.22)\end{array}$ & $\begin{array}{c}0.28 \\
(1.35)\end{array}$ & $\begin{array}{c}0.25 \\
(1.33)\end{array}$ & $\begin{array}{c}0.28 \\
(1.35)\end{array}$ & $\begin{array}{c}0.28 \\
(1.33)\end{array}$ & $\begin{array}{c}0.05 \\
(2.17)\end{array}$ & $\begin{array}{c}-0.02 \\
(-0.70)\end{array}$ & $\begin{array}{c}0.02 \\
(0.20)\end{array}$ & $\begin{array}{c}0.06 \\
(0.57)\end{array}$ & $\begin{array}{c}-0.02 \\
(-0.57)\end{array}$ & $\begin{array}{c}-0.02 \\
(-0.53)\end{array}$ \\
\hline$\beta_{M O M}$ & $\begin{array}{c}(-0.22) \\
0.39\end{array}$ & $\begin{array}{l}(1.35) \\
1.39\end{array}$ & $\begin{array}{l}(1.33) \\
1.25\end{array}$ & $\begin{array}{l}(1.35) \\
1.39\end{array}$ & $\begin{array}{l}(1.33) \\
1.38\end{array}$ & $\begin{array}{c}(2.17) \\
0.21\end{array}$ & $\begin{array}{c}(-0.70) \\
\mathbf{0 . 1 8}\end{array}$ & $\begin{array}{c}(0.20) \\
\mathbf{0 . 6 5}\end{array}$ & $\begin{array}{c}(0.57) \\
\mathbf{0 . 6 0}\end{array}$ & $\begin{array}{c}(-0.57) \\
\mathbf{0 . 2 9}\end{array}$ & $\begin{array}{c}(-0.53) \\
\mathbf{0 . 2 8}\end{array}$ \\
\hline PMOM & $(13.67)$ & $(9.14)$ & $(8.97)$ & $(9.15)$ & $(9.16)$ & $(8.71)$ & (6.09) & $(10.73)$ & $(9.77)$ & (9.99) & $(10.14)$ \\
\hline Adj. $R^{2}$ & 0.35 & 0.31 & 0.33 & 0.31 & 0.31 & 0.24 & 0.12 & 0.46 & 0.23 & 0.25 & 0.25 \\
\hline
\end{tabular}


Table 2: Risk and performance of term structure portfolios under various weighting schemes

Panel A presents summary statistics for the excess returns of long-short term structure portfolios under various weighting schemes. Panels B and C report parameter estimates, Newey-West t-statistics and adjusted $R^{2}$ obtained from regressions of the excess returns of a given naive or sophisticated strategy on the excess returns of the relevant risk factors. PU, NE, DA, MV, and MIN stand for power utility, negative exponential utility, power utility with disappointment aversion, mean variance utility, and minimum variance, respectively. VT, RRT, BT, VaRT and CVaRT stand for volatility timing, reward-to-risk timing, beta-timing, Value-at-Risk timing, and Conditional Valueat-Risk timing, respectively. Mean, volatility, downside volatility (relative to a zero excess return) and abnormal returns $(\alpha)$ have been annualized, Newey-West t-ratios are shown in parentheses, t-statistics for the null hypothesis that a given sophisticated strategy generates the same mean excess return as its equal-weight counterpart are reported under the heading "ew tstat". Bold fonts denote significance at the $5 \%$ level or better. Sharpe (Sortino) ratios are mean over volatility (downside volatility using $0 \%$ as threshold). Omega ratios are the probability of gains divided by the probability of losses using $0 \%$ as threshold. AVG is a long-only equally-weighted monthly-rebalanced portfolio of all commodity futures, CARRY and MOM are equally-weighted monthly-rebalanced long-short portfolios based on roll-yields and past performance, respectively. The analysis spans the sample January 1980 to April 2016.

\begin{tabular}{|c|c|c|c|c|c|c|c|c|c|c|c|}
\hline & \multirow{2}{*}{$\begin{array}{c}\text { Equal } \\
\text { Weights }\end{array}$} & \multicolumn{5}{|c|}{ Optimized weights } & \multicolumn{5}{|c|}{ Risk-timing weights } \\
\hline & & $\mathrm{PU}$ & $\mathrm{NE}$ & DA & MV & MIN & VT & RRT & BT & VaRT & CVaRT \\
\hline \multicolumn{12}{|c|}{ Panel A: Summary statistics } \\
\hline Mean & 0.0479 & 0.1041 & 0.0991 & 0.1041 & 0.1052 & 0.0409 & 0.0279 & 0.1149 & 0.1183 & 0.0387 & 0.0384 \\
\hline tstat & $(2.65)$ & $(0.81)$ & $(0.90)$ & $(0.81)$ & $(1.79)$ & $(3.52)$ & $(2.06)$ & $(3.58)$ & $(2.94)$ & $(2.46)$ & $(2.46)$ \\
\hline ew tstat & $(0.00)$ & $(-1.04)$ & $(-1.08)$ & $(-1.03)$ & $(-1.06)$ & $(0.83)$ & $(2.64)$ & $(-3.21)$ & $(-2.29)$ & $(2.10)$ & $(2.26)$ \\
\hline Volatility & 0.08 & 0.34 & 0.30 & 0.34 & 0.33 & 0.06 & 0.07 & 0.14 & 0.19 & 0.07 & 0.07 \\
\hline Downside volatility & 0.05 & 0.23 & 0.21 & 0.23 & 0.23 & 0.03 & 0.04 & 0.08 & 0.12 & 0.04 & 0.04 \\
\hline Skewness & 0.37 & -0.15 & -0.19 & -0.16 & -0.15 & 0.35 & 0.45 & 0.22 & 0.21 & 0.50 & 0.51 \\
\hline Ex. kurtosis & 3.30 & 3.58 & 3.84 & 3.58 & 3.57 & 1.76 & 3.61 & 1.67 & 3.94 & 3.24 & 3.39 \\
\hline JB p.value & 0.00 & 0.00 & 0.00 & 0.00 & 0.00 & 0.00 & 0.00 & 0.00 & 0.00 & 0.00 & 0.00 \\
\hline $\operatorname{VaR}(95 \%)$ & -0.03 & -0.14 & -0.12 & -0.14 & -0.14 & -0.02 & -0.03 & -0.06 & -0.07 & -0.03 & -0.03 \\
\hline CVaR (95\%) & -0.05 & -0.21 & -0.19 & -0.21 & -0.21 & -0.03 & -0.04 & -0.08 & -0.11 & -0.04 & -0.04 \\
\hline Max drawdown & 0.22 & 0.86 & 0.78 & 0.86 & 0.86 & 0.13 & 0.17 & 0.30 & 0.57 & 0.18 & 0.18 \\
\hline Sharpe ratio & 0.58 & 0.31 & 0.33 & 0.31 & 0.31 & 0.73 & 0.43 & 0.84 & 0.62 & 0.56 & 0.55 \\
\hline Sortino ratio & 0.91 & 0.45 & 0.48 & 0.45 & 0.46 & 1.24 & 0.67 & 1.40 & 0.97 & 0.91 & 0.90 \\
\hline Omega ratio & 1.57 & 1.28 & 1.31 & 1.28 & 1.28 & 1.76 & 1.41 & 1.91 & 1.65 & 1.55 & 1.54 \\
\hline \multicolumn{12}{|c|}{ Panel B: Regression analysis relative to the equal-weight benchmark } \\
\hline$\alpha$ & & $\begin{array}{c}0.0617 \\
(1.10)\end{array}$ & $\begin{array}{c}0.0547 \\
(1.12)\end{array}$ & $\begin{array}{c}0.0616 \\
(1.10)\end{array}$ & $\begin{array}{c}0.0630 \\
(1.13)\end{array}$ & $\begin{array}{c}\mathbf{0 . 0 1 5 0} \\
(3.07)\end{array}$ & $\begin{array}{c}-0.0035 \\
(-0.66)\end{array}$ & $\begin{array}{c}\mathbf{0 . 0 8 1 8} \\
(3.48)\end{array}$ & $\begin{array}{c}\mathbf{0 . 0 8 7 5} \\
(2.92)\end{array}$ & $\begin{array}{c}0.0003 \\
(0.09)\end{array}$ & $\begin{array}{c}-0.0005 \\
(-0.14)\end{array}$ \\
\hline$\beta$ & & $\begin{array}{c}\mathbf{0 . 8 9} \\
(2.92)\end{array}$ & $\begin{array}{c}\mathbf{0 . 9 3} \\
(3.42)\end{array}$ & $\begin{array}{c}\mathbf{0 . 8 9} \\
(2.92)\end{array}$ & $\begin{array}{c}\mathbf{0 . 8 8} \\
(2.92)\end{array}$ & $\begin{array}{c}\mathbf{0 . 5 4} \\
(12.59)\end{array}$ & $\begin{array}{c}\mathbf{0 . 6 6} \\
(18.16)\end{array}$ & $\begin{array}{c}\mathbf{0 . 6 9} \\
(4.71)\end{array}$ & $\begin{array}{c}\mathbf{0 . 6 4} \\
(2.85)\end{array}$ & $\begin{array}{c}\mathbf{0 . 8 0} \\
(44.30)\end{array}$ & $\begin{array}{c}\mathbf{0 . 8 1} \\
(44.03)\end{array}$ \\
\hline Adj. $R^{2}$ & & 0.05 & 0.07 & 0.05 & 0.05 & 0.64 & 0.70 & 0.18 & 0.08 & 0.91 & $\begin{array}{c}(44.00) \\
0.92\end{array}$ \\
\hline \multicolumn{12}{|c|}{ Panel C: Regression analysis relative to the Bakshi et al. (2017) benchmark } \\
\hline$\alpha$ & $\begin{array}{c}\mathbf{0 . 0 3 0 6} \\
(3.65)\end{array}$ & $\begin{array}{c}0.0058 \\
(0.11)\end{array}$ & $\begin{array}{c}0.0087 \\
(0.19)\end{array}$ & $\begin{array}{c}0.0058 \\
(0.11)\end{array}$ & $\begin{array}{c}0.0075 \\
(0.15)\end{array}$ & $\begin{array}{c}\mathbf{0 . 0 2 6 5} \\
(4.19)\end{array}$ & $\begin{array}{c}\mathbf{0 . 0 2 1 4} \\
(2.52)\end{array}$ & $\begin{array}{c}\mathbf{0 . 0 6 6 6} \\
(3.47)\end{array}$ & $\begin{array}{c}\mathbf{0 . 0 6 0 5} \\
(2.08)\end{array}$ & $\begin{array}{c}\mathbf{0 . 0 2 6 3} \\
(3.22)\end{array}$ & $\begin{array}{c}\mathbf{0 . 0 2 6 3} \\
(3.31)\end{array}$ \\
\hline$\beta_{A V G}$ & -0.42 & 0.11 & 0.05 & 0.11 & 0.10 & -0.17 & -0.31 & -0.08 & 0.26 & -0.35 & -0.36 \\
\hline & $(-9.84)$ & $(0.59)$ & $(0.32)$ & $(0.59)$ & $(0.57)$ & $(-6.20)$ & $(-8.33)$ & $(-0.78)$ & $(1.60)$ & $(-9.57)$ & $(-10.21)$ \\
\hline$\beta_{C A R R Y}$ & $\begin{array}{c}\mathbf{0 . 4 0} \\
(14.46)\end{array}$ & $\begin{array}{c}\mathbf{0 . 6 2} \\
(3.03)\end{array}$ & $\begin{array}{c}\mathbf{0 . 6 1} \\
(3.36)\end{array}$ & $\begin{array}{c}\mathbf{0 . 6 2} \\
(3.03)\end{array}$ & $\begin{array}{c}\mathbf{0 . 6 2} \\
(3.02)\end{array}$ & $\begin{array}{c}\mathbf{0 . 2 8} \\
(9.54)\end{array}$ & $\begin{array}{c}\mathbf{0 . 2 1} \\
(5.09)\end{array}$ & $\begin{array}{c}\mathbf{0 . 3 8} \\
(4.62)\end{array}$ & $\begin{array}{c}\mathbf{0 . 5 6} \\
(5.12)\end{array}$ & $\begin{array}{c}\mathbf{0 . 3 0} \\
(10.26)\end{array}$ & $\begin{array}{c}\mathbf{0 . 3 0} \\
(10.81)\end{array}$ \\
\hline$\beta_{M O M}$ & $\begin{array}{c}(14.40) \\
-0.03\end{array}$ & 1.08 & 0.95 & 1.08 & 1.07 & $\begin{array}{l}(9.54) \\
-0.02\end{array}$ & $\begin{array}{l}(5.09) \\
-0.04\end{array}$ & $\begin{array}{c}(4.62) \\
\mathbf{0 . 4 7}\end{array}$ & 0.33 & $\begin{array}{l}(10.26) \\
-0.02\end{array}$ & $\begin{array}{l}(10.81) \\
-0.02\end{array}$ \\
\hline & $(-1.05)$ & $(8.11)$ & $(8.19)$ & $(8.11)$ & $(8.12)$ & $(-1.12)$ & $(-1.42)$ & $(10.88)$ & $(4.61)$ & $(-0.68)$ & $(-0.96)$ \\
\hline Adj. $R^{2}$ & 0.68 & 0.26 & 0.28 & 0.26 & 0.26 & 0.46 & 0.46 & 0.38 & 0.23 & 0.62 & 0.63 \\
\hline
\end{tabular}


Table 3: Transaction costs

The table studies the impact of transaction costs on the performance of various momentum (Panel A) and term structure (Panel B) strategies. Turnover measures the monthly average number of trades per strategy. Net mean excess returns and net Sharpe ratios are computed after deducting from the gross returns round-trip transaction costs of 8.6 b.p. PU, NE, DA, MV, and MIN stand for power utility, negative exponential utility, power utility with disappointment aversion, mean variance, and minimum variance, respectively. VT, RRT, BT, VaRT, and CVaRT stand for volatility timing, reward-to-risk timing, beta-timing, Value-at-Risk timing and Conditional Value-at-Risk timing, respectively. Bold fonts denote significance at the $5 \%$ level or better and t-ratios are shown in parentheses. The analysis spans the sample January 1980 to April 2016.

\begin{tabular}{|c|c|c|c|c|c|c|c|c|c|c|c|}
\hline & \multirow[b]{2}{*}{ EW } & \multicolumn{5}{|c|}{ Optimized weights } & \multicolumn{5}{|c|}{ Risk-timing weights } \\
\hline & & PU & $\mathrm{NE}$ & $\mathrm{DA}$ & MV & MIN & VT & RRT & $\mathrm{BT}$ & VaRT & CVaRT \\
\hline \multicolumn{12}{|c|}{$\begin{array}{l}\text { Panel A: Momentum strategies } \\
\text { Monthly turnover }\end{array}$} \\
\hline Mean & 1.52 & 1.71 & 1.68 & 1.71 & 1.73 & 1.58 & 1.58 & 1.59 & 1.66 & 1.56 & 1.55 \\
\hline Median & 1.49 & 1.99 & 1.88 & 1.99 & 1.99 & 1.60 & 1.58 & 1.61 & 1.70 & 1.55 & 1.53 \\
\hline Minimum & 0.75 & 0.01 & 0.16 & 0.01 & 0.00 & 0.45 & 0.59 & 0.69 & 0.61 & 0.72 & 0.70 \\
\hline Maximum & 2.00 & 2.00 & 2.00 & 2.00 & 2.00 & 2.00 & 2.00 & 2.00 & 2.00 & 2.00 & 2.00 \\
\hline \multirow{2}{*}{ Net Mean return } & 0.05 & 0.06 & 0.06 & 0.06 & 0.06 & 0.04 & 0.04 & 0.08 & 0.06 & 0.05 & 0.05 \\
\hline & $(3.80)$ & $(1.06)$ & $(1.22)$ & $(1.06)$ & $(1.35)$ & $(4.23)$ & $(4.04)$ & $(3.55)$ & $(2.39)$ & $(4.06)$ & $(4.08)$ \\
\hline Net Sharpe ratio & 0.55 & 0.16 & 0.18 & 0.16 & 0.17 & 0.70 & 0.67 & 0.57 & 0.34 & 0.65 & 0.65 \\
\hline \multicolumn{12}{|c|}{ Panel B: Term structure strategies } \\
\hline Mean & 1.57 & 1.76 & 1.73 & 1.76 & 1.76 & 1.64 & 1.61 & 1.64 & 1.73 & 1.58 & 1.57 \\
\hline Median & 1.54 & 2.00 & 1.92 & 2.00 & 2.00 & 1.64 & 1.61 & 1.69 & 1.84 & 1.56 & 1.54 \\
\hline Minimum & 0.84 & 0.01 & 0.17 & 0.01 & 0.01 & 0.76 & 0.62 & 0.71 & 0.56 & 0.75 & 0.71 \\
\hline Maximum & 2.00 & 2.00 & 2.00 & 2.00 & 2.00 & 2.00 & 2.00 & 2.00 & 2.00 & 2.00 & 2.00 \\
\hline \multirow[t]{2}{*}{ Net Mean return } & 0.03 & 0.09 & 0.08 & 0.09 & 0.09 & 0.02 & 0.01 & 0.10 & 0.10 & 0.02 & 0.02 \\
\hline & $(2.65)$ & $(0.81)$ & $(0.90)$ & $(0.81)$ & $(1.79)$ & $(3.52)$ & $(2.06)$ & $(3.58)$ & $(2.94)$ & $(2.46)$ & $(2.46)$ \\
\hline Net Sharpe ratio & 0.38 & 0.26 & 0.27 & 0.26 & 0.26 & 0.43 & 0.15 & 0.72 & 0.53 & 0.32 & 0.32 \\
\hline
\end{tabular}


Table 4: Liquidity risk

The table studies the impact of lack of liquidity on the performance of various momentum (Panel A) and term structure (Panel B) strategies. SR(All) and SR(Liquid) are the Sharpe ratios of the strategies when implemented on the whole cross section and the $90 \%$ cross section that presents the highest liquidity ratios (Amihud et al., 1997), respectively. $\alpha, \beta_{L I Q}$, Newey-West t-statistics and adjusted- $R^{2}$ are obtained from regressions of the excess returns of a given naive or sophisticated strategy on the excess returns of the three-factor benchmark of Bakshi et al. (2017) augmented with a liquidity risk premium (LIQ). Alpha has been annualized. PU, NE, DA, MV, and MIN stand for power utility, negative exponential utility, power utility with disappointment aversion, mean variance utility, and minimum variance, respectively. VT, RRT, BT, VaRT, and CVaRT stand for volatility timing, reward-to-risk timing, beta-timing, Value-at-Risk timing and Conditional Value-at-Risk timing, respectively. Bold fonts denote significance at the $5 \%$ level or better. The analysis spans the sample January 1980 to April 2016.

\begin{tabular}{|c|c|c|c|c|c|c|c|c|c|c|c|}
\hline & \multirow{2}{*}{$\begin{array}{c}\text { Equal } \\
\text { Weights }\end{array}$} & \multicolumn{5}{|c|}{ Optimized weights } & \multicolumn{5}{|c|}{ Risk-timing weights } \\
\hline & & $\mathrm{PU}$ & $\mathrm{NE}$ & DA & MV & MIN & VT & RRT & BT & VaR & CVaR \\
\hline \multicolumn{12}{|c|}{ Panel A: Momentum strategies } \\
\hline SR (all) & 0.74 & 0.21 & 0.24 & 0.21 & 0.22 & 0.97 & 0.95 & 0.69 & 0.44 & 0.87 & 0.87 \\
\hline SR (Liquid) & 0.69 & 0.10 & 0.11 & 0.10 & 0.63 & 0.92 & 0.91 & 0.63 & 0.43 & 0.84 & 0.83 \\
\hline$\alpha$ & $\begin{array}{c}\mathbf{0 . 0 4 4 3} \\
(4.28)\end{array}$ & $\begin{array}{c}-0.0204 \\
(-0.37)\end{array}$ & $\begin{array}{r}-0.0135 \\
(-0.28)\end{array}$ & $\begin{array}{c}-0.0205 \\
(-0.37)\end{array}$ & $\begin{array}{c}-0.0162 \\
(-0.29)\end{array}$ & $\begin{array}{c}\mathbf{0 . 0 4 4 0} \\
(5.31)\end{array}$ & $\begin{array}{c}\mathbf{0 . 0 5 3 6} \\
(5.35)\end{array}$ & $\begin{array}{c}\mathbf{0 . 0 5 3 6} \\
(3.14)\end{array}$ & $\begin{array}{c}0.0386 \\
(1.35)\end{array}$ & $\begin{array}{c}\mathbf{0 . 0 4 9 9} \\
(5.18)\end{array}$ & $\begin{array}{r}\mathbf{0 . 0 4 9 4} \\
(5.16)\end{array}$ \\
\hline$\beta_{L I Q}$ & $\begin{array}{c}-0.04 \\
(-0.89)\end{array}$ & $\begin{array}{c}-0.03 \\
(-0.13)\end{array}$ & $\begin{array}{c}-0.00 \\
(-0.00)\end{array}$ & $\begin{array}{c}-0.03 \\
(-0.13)\end{array}$ & $\begin{array}{c}-0.04 \\
(-0.17)\end{array}$ & $\begin{array}{c}0.00 \\
(0.03)\end{array}$ & $\begin{array}{c}-0.01 \\
(-0.42)\end{array}$ & $\begin{array}{c}0.00 \\
(-0.02)\end{array}$ & $\begin{array}{c}0.05 \\
(0.36)\end{array}$ & $\begin{array}{c}-0.02 \\
(-0.60)\end{array}$ & $\begin{array}{l}-0.02 \\
(-0.61)\end{array}$ \\
\hline$A d j-R^{2}$ & 0.36 & 0.31 & 0.33 & 0.31 & 0.31 & 0.24 & 0.13 & 0.46 & 0.23 & 0.26 & 0.26 \\
\hline \multicolumn{12}{|c|}{ Panel B: Term stucture strategies } \\
\hline SR (all) & 0.58 & 0.31 & 0.33 & 0.31 & 0.31 & 0.73 & 0.43 & 0.84 & 0.62 & 0.56 & 0.55 \\
\hline SR (Liquid) & 0.47 & 0.21 & 0.21 & 0.21 & 0.22 & 0.60 & 0.36 & 0.67 & 0.52 & 0.46 & 0.46 \\
\hline$\alpha$ & $\mathbf{0 . 0 2 8 6}$ & $\begin{array}{c}0.0145 \\
(0.28)\end{array}$ & $\begin{array}{c}0.0149 \\
(0.33)\end{array}$ & $\begin{array}{c}0.0145 \\
(0.28)\end{array}$ & $\begin{array}{c}0.0166 \\
(0.33)\end{array}$ & $\mathbf{0 . 0 2 5 6}$ & $\mathbf{0 . 0 1 8 8}$ & $\begin{array}{c}\mathbf{0 . 0 6 7 3} \\
(3.48)\end{array}$ & 0.0552 & $\mathbf{0 . 0 2 3 5}$ & 0.0236 \\
\hline$\beta_{L I Q}$ & $\begin{array}{l}(3.42) \\
0.04\end{array}$ & $\begin{array}{l}(0.28) \\
-0.16\end{array}$ & $\begin{array}{l}(0.33) \\
-0.12\end{array}$ & $\begin{array}{l}(0.28) \\
-0.16\end{array}$ & $\begin{array}{l}(0.33) \\
-0.17\end{array}$ & $\begin{array}{c}(3.98) \\
0.02\end{array}$ & $\begin{array}{c}(2.08) \\
0.05\end{array}$ & $\begin{array}{l}(3.48) \\
-0.01\end{array}$ & $\begin{array}{c}(1.93) \\
0.10\end{array}$ & $\begin{array}{l}(2.78) \\
0.05\end{array}$ & $\begin{array}{l}(2.87) \\
0.05\end{array}$ \\
\hline & $(1.74)$ & $(-0.88)$ & $(-0.70)$ & $(-0.88)$ & $(-0.92)$ & $(0.67)$ & $(1.67)$ & $(-0.22)$ & $(0.91)$ & $(2.32)$ & $(2.18)$ \\
\hline $\operatorname{Adj}-R^{2}$ & 0.68 & 0.27 & 0.28 & 0.27 & 0.27 & 0.47 & 0.47 & 0.38 & 0.23 & 0.63 & 0.64 \\
\hline
\end{tabular}


Table 5: Model parameters

The table studies the sensitivity of the Sharpe ratios of various momentum (Panel A) and term structure (Panel B) strategies to the choice of weighting ranking periods $\left(R_{\text {weight }}\right)$, momentum ranking periods $\left(R_{\text {mom }}\right)$, holding period $(H)$, and tuning parameter $(\eta)$. PU, NE, DA, MV, and MIN stand for power utility, negative exponential utility, power utility with disappointment aversion, mean variance, and minimum variance, respectively. VT, RRT, BT, VaRT, and CVaRT stand for volatility timing, reward-to-risk timing, beta-timing, Value-at-Risk timing and Conditional Value-at-Risk timing, respectively. The analysis spans the sample January 1980 to April 2016.

\begin{tabular}{|c|c|c|c|c|c|c|c|c|c|c|c|}
\hline & \multirow{2}{*}{$\begin{array}{c}\text { Equal } \\
\text { Weights }\end{array}$} & \multicolumn{5}{|c|}{ Optimized weights } & \multicolumn{5}{|c|}{ Risk-timing weights } \\
\hline & & $\mathrm{PU}$ & $\mathrm{NE}$ & DA & MV & MIN & $\mathrm{VT}$ & RRT & $\mathrm{BT}$ & VaR & CVaR \\
\hline \multicolumn{12}{|c|}{ Panel A: Momentum-based strategies } \\
\hline$R_{\text {weight }}=3$ & 0.74 & 0.17 & 0.17 & 0.17 & 0.18 & 0.91 & 0.79 & 0.71 & 0.54 & 0.87 & 0.69 \\
\hline$R_{\text {weight }}=6$ & 0.74 & 0.12 & 0.15 & 0.12 & 0.13 & 1.03 & 0.86 & 0.68 & 0.52 & 0.84 & 0.85 \\
\hline$R_{\text {weight }}=18$ & 0.76 & -0.11 & -0.06 & -0.11 & -0.10 & 0.96 & 0.92 & 0.36 & 0.40 & 0.85 & 0.87 \\
\hline$R_{m o m}=3$ & 0.86 & 0.36 & 0.39 & 0.36 & 0.37 & 0.81 & 0.94 & 0.79 & 0.47 & 0.94 & 0.91 \\
\hline$R_{m o m}=6$ & 0.65 & 0.20 & 0.22 & 0.20 & 0.21 & 0.84 & 0.77 & 0.67 & 0.35 & 0.77 & 0.76 \\
\hline$H=2$ & 0.69 & 0.11 & 0.14 & 0.11 & 0.32 & 0.94 & 0.78 & 0.56 & 0.40 & 0.76 & 0.77 \\
\hline$H=4$ & 0.35 & 0.10 & 0.10 & 0.10 & 0.11 & 0.50 & 0.41 & 0.34 & 0.24 & 0.39 & 0.40 \\
\hline$\eta=2$ & & & & & & & 0.73 & 0.56 & 0.44 & 0.89 & 0.92 \\
\hline$\eta=4$ & & & & & & & 0.53 & 0.48 & 0.45 & 0.75 & 0.85 \\
\hline \multicolumn{12}{|c|}{ Panel B: Term structure-based strategies } \\
\hline$R_{\text {weight }}=3$ & 0.36 & 0.05 & 0.05 & 0.05 & 0.05 & 0.40 & 0.28 & 0.65 & 0.51 & 0.41 & 0.43 \\
\hline$R_{\text {weight }}=6$ & 0.40 & -0.05 & -0.03 & -0.05 & -0.05 & 0.46 & 0.29 & 0.63 & 0.54 & 0.40 & 0.39 \\
\hline$R_{\text {weight }}=18$ & 0.47 & 0.08 & 0.11 & 0.08 & 0.08 & 0.60 & 0.34 & 0.38 & 0.41 & 0.40 & 0.41 \\
\hline$H=2$ & 0.50 & 0.24 & 0.26 & 0.24 & 0.24 & 0.69 & 0.40 & 0.68 & 0.54 & 0.51 & 0.50 \\
\hline$H=4$ & 0.54 & 0.18 & 0.19 & 0.18 & 0.19 & 0.58 & 0.33 & 0.37 & 0.42 & 0.45 & 0.46 \\
\hline$\eta=2$ & & & & & & & 0.19 & 0.66 & 0.64 & 0.47 & 0.49 \\
\hline$\eta=4$ & & & & & & & 0.08 & 0.55 & 0.64 & 0.32 & 0.39 \\
\hline
\end{tabular}


Table 6: Sub-sample analysis

The table studies the sensitivity of the Sharpe ratios of various momentum (Panel A) and term structure (Panel B) strategies to different subsamples. PU, NE, DA, MV, and MIN stand for power utility, exponential utility, power utility with disappointment aversion, mean variance, and minimum variance, respectively. VT, RRT, BT, VaRT, and CVaRT stand for volatility timing, reward-to-risk timing, beta-timing, Value-at-Risk timing, and Conditional Value-at-Risk timing, respectively. Periods of heightened versus reduced volatility in commodity (or equity) markets is defined relative to the long-term average S\&P-GSCI (S\&P500) conditional volatility estimated from a GARCH(1,1) model.

\begin{tabular}{|c|c|c|c|c|c|c|c|c|c|c|c|}
\hline & \multirow{2}{*}{$\begin{array}{c}\text { Equal } \\
\text { Weights }\end{array}$} & \multicolumn{5}{|c|}{ Optimized weights } & \multicolumn{5}{|c|}{ Risk-timing weights } \\
\hline & & PU & $\mathrm{NE}$ & DA & MV & MIN & VT & RRT & BT & VaR & CVaR \\
\hline \multicolumn{12}{|l|}{ Panel A: Momentum strategies } \\
\hline Pre financialization & 0.98 & 0.26 & 0.28 & 0.26 & 0.27 & 1.18 & 1.15 & 0.81 & 0.71 & 1.12 & 1.13 \\
\hline Post financialization & 0.29 & 0.08 & 0.10 & 0.08 & 0.08 & 0.63 & 0.63 & 0.40 & -0.16 & 0.48 & 0.45 \\
\hline Low S\&P-GSCI volatility & 1.01 & 0.60 & 0.62 & 0.60 & 0.61 & 1.27 & 1.15 & 0.99 & 0.76 & 1.15 & 1.12 \\
\hline High S\&P-GSCI volatility & 0.52 & -0.19 & -0.16 & -0.19 & -0.18 & 0.79 & 0.79 & 0.46 & 0.22 & 0.66 & 0.67 \\
\hline Low S\&P-500 volatility & 0.85 & 0.31 & 0.35 & 0.31 & 0.32 & 1.12 & 1.07 & 0.90 & 0.58 & 1.02 & 0.97 \\
\hline High S\&P-500 volatility & 0.64 & 0.07 & 0.09 & 0.07 & 0.08 & 0.81 & 0.81 & 0.49 & 0.29 & 0.73 & 0.77 \\
\hline Jan $80-$ Mar 87 & 0.71 & 0.16 & 0.16 & 0.16 & 0.18 & 1.15 & 0.92 & 0.46 & 0.15 & 0.84 & 0.87 \\
\hline Apr 87 - Jun 94 & 0.95 & 0.74 & 0.77 & 0.74 & 0.74 & 1.06 & 1.14 & 0.95 & 0.72 & 1.08 & 1.10 \\
\hline Jul 94 - Sep 01 & 1.64 & 0.29 & 0.33 & 0.29 & 0.29 & 2.27 & 1.85 & 1.24 & 1.23 & 1.90 & 1.87 \\
\hline Oct $01-$ Dec 08 & 0.68 & -0.06 & 0.01 & -0.06 & -0.04 & 0.86 & 0.99 & 0.84 & 0.32 & 0.85 & 0.85 \\
\hline Jan 09 - Apr 16 & 0.02 & -0.12 & -0.12 & -0.12 & -0.12 & 0.37 & 0.39 & 0.09 & -0.22 & 0.22 & 0.19 \\
\hline \multicolumn{12}{|c|}{ Panel B: Term structure strategies } \\
\hline Pre financialization & 0.79 & 0.36 & 0.38 & 0.36 & 0.36 & 0.83 & 0.64 & 1.00 & 0.98 & 0.81 & 0.80 \\
\hline Post financialization & 0.12 & 0.17 & 0.19 & 0.17 & 0.17 & 0.55 & 0.01 & 0.49 & -0.19 & 0.08 & 0.08 \\
\hline Low S\&P-GSCI volatility & 0.76 & 0.62 & 0.64 & 0.62 & 0.62 & 0.87 & 0.65 & 1.00 & 0.92 & 0.77 & 0.76 \\
\hline High S\&P-GSCI volatility & 0.43 & -0.04 & -0.01 & -0.04 & -0.04 & 0.63 & 0.26 & 0.69 & 0.44 & 0.39 & 0.39 \\
\hline Low S\&P-500 volatility & 0.61 & 0.40 & 0.43 & 0.40 & 0.40 & 0.76 & 0.45 & 0.95 & 0.83 & 0.56 & 0.51 \\
\hline High S\&P-500 volatility & 0.57 & 0.16 & 0.19 & 0.16 & 0.17 & 0.70 & 0.42 & 0.70 & 0.38 & 0.57 & 0.61 \\
\hline Jan $80-$ Mar 87 & 0.79 & 0.74 & 0.73 & 0.74 & 0.75 & 0.71 & 0.67 & 0.94 & 0.72 & 0.78 & 0.85 \\
\hline Apr 87 - Jun 94 & 0.92 & 0.56 & 0.61 & 0.56 & 0.57 & 0.98 & 1.34 & 1.14 & 1.15 & 1.16 & 1.10 \\
\hline Jul 94 - Sep 01 & 1.27 & 0.29 & 0.31 & 0.29 & 0.29 & 1.50 & 0.81 & 1.22 & 1.11 & 1.34 & 1.22 \\
\hline Oct $01-$ Dec 08 & 0.26 & 0.00 & 0.02 & 0.00 & 0.02 & 0.39 & 0.07 & 1.01 & 0.45 & 0.19 & 0.18 \\
\hline Jan 09 - Apr 16 & -0.05 & -0.13 & -0.11 & -0.13 & -0.13 & 0.49 & -0.11 & 0.02 & -0.21 & -0.10 & -0.08 \\
\hline
\end{tabular}

